\title{
Fission yeast Ccq1 is telomerase recruiter and local checkpoint controller
}

\author{
Kazunori Tomita and Julia Promisel Cooper ${ }^{1}$ \\ Telomere Biology Laboratory, Cancer Research UK, London WC2A 3PX, United Kingdom
}

Telomeres recruit telomerase and differentiate chromosome ends from sites of DNA damage. Although the DNA damage checkpoint PI3-kinases ATM and ATR localize to telomeres and promote telomerase activation, activation of their downstream checkpoint pathway targets is inhibited. Here, we show that the fission yeast telomeric protein Ccq1 is required for telomerase recruitment and inhibition of ATR target activation at telomeres. The loss of Ccq1 results in progressive telomere shortening and persistent ATR-dependent activation of Chk1. Unlike the checkpoint activation that follows loss of telomerase, this checkpoint activation occurs prior to detectable levels of critically short telomeres. When ccq1s telomeres do become critically short, activated Chk1 promotes an unusual homologous recombination-based telomere maintenance process. We find that the previously reported meiotic segregation defects of cells lacking Ccq1 stem from its role in telomere maintenance rather than from a role in formation of the meiotic bouquet. These findings demonstrate the existence of a novel telomerase recruitment factor that also serves to suppress local checkpoint activation.

[Keywords: Telomere; telomerase; DNA damage checkpoint; homologous recombination; mitosis; meiosis]

Supplemental material is available at http://www.genesdev.org.

Received July 25, 2008; revised version accepted October 31, 2008.

The telomeric repeats that comprise terminal chromosomal DNA assemble protein complexes that differentiate bona fide chromosomal ends from damaged DNA. Hence, telomeres prevent chromosome ends from eliciting their own fusion and recombination, and from triggering checkpoint-induced cell cycle arrest. Nonetheless, numerous DNA damage response proteins, including MRN (the Mre11-Rad50-Nbs1 complex), Ku, ATM, and ATR, localize to telomeres and play important roles in normal telomere metabolism /Gravel et al. 1998; Zhu et al. 2000; Nakamura et al. 2002; Takata et al. 2005; Verdun and Karlseder 2006). How telomeres prevent these factors from inappropriately responding to chromosome ends is one of the persisting mysteries of chromosome biology.

Telomeric DNA is degraded every cell cycle in a replication-associated manner. Critically short telomeres lose the ability to protect chromosome ends from being recognized as DNA damage. Accordingly, short telomeres elicit the cell cycle arrest pathways that robust telomeres inhibit, leading to cellular senescence or apoptosis. In order to maintain proliferation, germ cells, cancer cells, and unicellular organisms employ the telomere-specific reverse transcriptase, telomerase, to replenish terminal telomere repeats. Telomerase activity can be reconstituted in vitro from only two essential

${ }^{1}$ Corresponding author.

E-MAIL Julie.cooper@cancer.org.uk; FAX 44-0207-2693258.

Article is online at http://www.genesdev.org/cgi/doi/10.1101/gad.498608. components, the catalytic protein subunit of the reverse transcriptase and the telomeric RNA template (Lingner et al. 1997). However, in vivo telomerase activity requires several additional subunits that mediate the recruitment and activation of telomerase in a telomere attrition- and cell cycle-dependent manner (Taggart et al. 2002; Teixeira et al. 2004; Bianchi and Shore 2007; Sabourin et al. 2007). Regulation of telomerase activity is so far best understood in budding yeast. Recruitment of Est2 (the catalytic subunit) to short telomeres in late $\mathrm{S}$ phase is mediated by the telomerase-binding protein Est1, which in turn associates with TLC1 (the telomerase RNA) and the single-stranded telomeric DNA-binding protein Cdc13 (Singer and Gottschling 1994; Lin and Zakian 1995; Lendvay et al. 1996; Nugent et al. 1996; Evans and Lundblad 1999; Qi and Zakian 2000; Taggart et al. 2002; Bianchi et al. 2004; Sabourin et al. 2007); modification of one or more telomere components by ATM/ATR confers at least part of the telomere attrition and cell cycle dependence of telomerase activation (Takata et al. 2005; Tseng et al. 2006). In fission yeast, the telomerase complex contains Trt1 (the Est2 homolog), the RNA template Ter1, and Est1 (Nakamura et al. 1997; Beernink et al. 2003; Leonardi et al. 2008; Webb and Zakian 2008). In addition, telomere maintenance requires the telomere single-strand-binding protein Pot1 (Baumann and Cech 2001). The Pot1 complex has recently been purified and found to contain three additional proteins-Tpz1, Poz1, and Ccq1 (see below) (Mi- 
yoshi et al. 2008). In human cells, hTERT (the Est2 homolog) and the RNA template hTR are known telomerase components (Feng et al. 1995; Meyerson et al. 1997). A human Est1 homolog, hEST1A, associates with hTERT, and diminution of hEST1A function leads to telomere loss (Reichenbach et al. 2003; Snow et al. 2003; Azzalin et al. 2007). Human POT1 binds to the single-strand telomeric overhang in a manner that requires an additional protein, TPP1; POT1 and TPP1 associate with the core double-strand telomere-binding complex, shelterin (Baumann and Cech 2001; Ye et al. 2004; de Lange 2005), and are found to associate with telomerase in vivo (Wang et al. 2007; Xin et al. 2007). However, the mechanism of telomerase recruitment in fission yeast and human remains elusive.

A fraction of cancer cells are known to maintain their telomeres via recombination-mediated telomere replication using other chromosomal ends as template. This telomerase-independent telomere maintenance process is termed "ALT" (alternative lengthening of telomeres) (Bryan et al. 1995; Bryan and Reddel 1997). A similar phenomenon is observed in survivors of telomerase inactivation in budding and fission yeasts (Lundblad and Blackburn 1993; Nakamura et al. 1998; Subramanian et al. 2008). In yeast, two types of recombination survivors have been characterized, "Type I" and "Type II" (Le et al. 1999). Although both require the recombination protein Rad52, Type I survivors require Rad51, Rad54, and Rad57 and sustain amplification of subtelomeric repeats along with short stretches of telomere repeat sequence at each chromosome terminus, while Type II survivors require Rad50, Rad59, and Sgs1 (RecQ homolog) and maintain heterogeneously long tracts of telomere repeats (Le et al. 1999; Chen et al. 2001; Huang et al. 2001).

Telomeric DNA-binding proteins are crucial for regulation of telomerase and protection of chromosomal ends. Fission yeast Taz1, and vertebrate TRF1 and TRF2, the double-stranded telomeric DNA-binding proteins, recruit Rap 1 and negatively regulate telomerase activity (Cooper et al. 1997; van Steensel and de Lange 1997; Li et al. 2000; Smogorzewska et al. 2000; Chikashige and Hiraoka 2001; Kanoh and Ishikawa 2001). In addition, fission yeast Taz1 and Rap1 suppress excessive resection of the telomeric C-strand (Tomita et al. 2003; Miller et al. 2005). Telomeres lacking Taz1 or TRF2 sustain telomere fusions mediated by the nonhomologous end-joining pathway (NHEJ) (van Steensel et al. 1998; Karlseder et al. 1999; Ferreira and Cooper 2001). Elimination of TRF2 activates the ATM-dependent checkpoint (Denchi and de Lange 2007). Vertebrate Pot1 and budding yeast Cdc13p suppress excessive resection of the telomeric Cstrand and suppress activation of the DNA damage checkpoint proteins ATR and 53BP1 ( $\operatorname{Rad} 9$ in yeast) (Garvik et al. 1995; Churikov et al. 2006; Hockemeyer et al. 2006; Wu et al. 2006; Denchi and de Lange 2007). Hence, these proteins confer a local DNA damage response suppression effect (Diede and Gottschling 1999; Michelson et al. 2005).

During early stages of meiosis, telomeres take on an additional role as they gather at the nuclear periphery to form the so-called "bouquet," which promotes efficient meiotic recombination and meiotic spindle formation. During meiotic prophase in fission yeast, the telomerebound Taz1-Rap1 complex associates with the meiosisspecific Bqt1-2 complex, which recruits the telomeres to the spindle pole body (SPB, the yeast centrosome) (Chikashige et al. 2006). The absence of Taz1, Rap1, Bqt1, or Bqt2 results in defective bouquet formation, which in turn causes severe defects in SPB duplication and meiotic spindle formation (Cooper et al. 1998; Chikashige and Hiraoka 2001; Kanoh and Ishikawa 2001; Chikashige et al. 2006; Tomita and Cooper 2007).

The fission yeast telomeric protein Ccq1 was first identified as a component of the supernumerary SPBs produced upon overexpression of the SPB subunit Pcp1 (Flory et al. 2004). Ccq1 was shown to colocalize with Taz1, and fluorescence resonance energy transfer analysis suggested that it also bound to the C terminus of Pcp1 during the meiotic bouquet stage. Deletion of $c c q 1^{+}$was reported to result in telomeric shortening, abnormally elongated cells, chromosome segregation failure, and defective telomere clustering during meiotic prophase (Flory et al. 2004). However, the relationship between these phenotypes remained unclear. Subsequently, Ccq1 was isolated via its interaction with the histone deacetylase complex SHREC (Snf2/Hdac-containing Repressor Complex) (Sugiyama et al. 2007), and very recently, Ccq1 was isolated as a component of the Pot l complex (Miyoshi et al. 2008). In an attempt to exploit the role of Ccq1 in bouquet formation, we found that it was, in fact, dispensable for bouquet formation. Instead, surprisingly, we found that Ccql is crucial for telomerase recruitment and telomere maintenance. Furthermore, Ccq1 is a repressor of ATR-dependent Chk1 activation at telomeres.

\section{Results}

Ccq1 is required for telomerase recruitment to telomeres and telomerase-mediated telomere synthesis

Loss of telomerase activity results in progressive telomere shortening with successive cell generations. To investigate whether the short telomeres seen in ccq1 $1 \Delta$ cells are due to a telomerase defect, heterozygous $c c q 1^{+/ \Delta}$ diploids were sporulated, and telomere length was monitored in the ccq1 $1 \Delta$ offspring over time. For comparison, trt1s strains were examined side-by-side using the same protocol. $c c q 1 \Delta$ cells exhibited progressive telomere short-

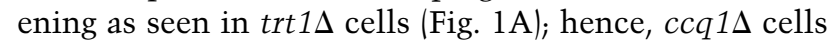
exhibit the classic "EST (ever shorter telomeres)" phenotype. This telomere shortening was accompanied by rearrangements of subtelomeric sequences (STE1: subtelomere 1) (see diagram in Fig. 1C), evidenced by the progressive accumulation of variable subtelomeric NsiI restriction fragment sizes (Fig. 1B; Nakamura et al. 1998).

To extend telomeric DNA, telomerase needs to be at telomeres. Hence, the resemblance between $c c q 1 \Delta$ and trt1 $1 \Delta$ telomeres may imply that telomerase recruitment 
A

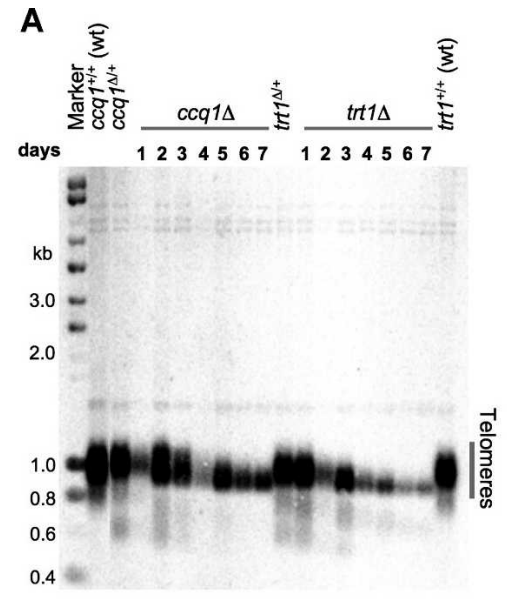

B

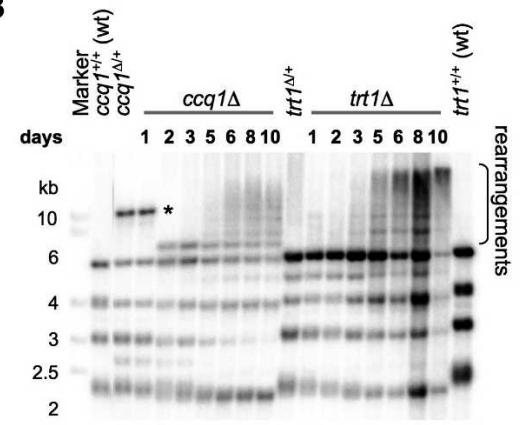

C

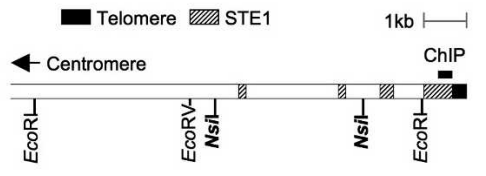

E

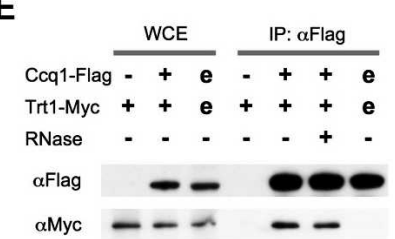

Figure 1. Ccq1 recruits telomerase to telomeres in vivo. $(A, B) c c q 1^{+}$deletion causes progressive telomere shortening and subtelomeric rearrangements. Diploids heterozygous for either ccq1s (ccq1::hygMX6/+) or $\operatorname{trt} 1 \Delta(\operatorname{trt} 1:: h y g M X 6 /+)$ were sporulated and germinated under selection for the respective gene deletions. Cultures were then collected every $24 \mathrm{~h}$ to obtain genomic DNA. Numbers above lanes indicate days post-germination. (A) Genomic DNA was digested with EcoRI. Telomeres (indicated by vertical gray bar) were detected with a synthetic telomeric repeat probe (Miller et al. 2006). (B) Genomic DNA was digested with NsiI. Subtelomeric rearrangements were detected with the STE1 (subtelomeric element 1) probe diagrammed in $C$. Note: The large band seen in lanes 3 and 4 (asterisk) is variably present in wild-type (wt) and mutant strains; its presence does not vary systematically with $c c q 1$ or trt1 status. In contrast, the subtelomeric rearrangements indicated to the right of the blot appear specifically and reproducibly with increasing time following $c c q 1^{+}$or $\operatorname{trt} 1^{+}$deletion (as in $B$; data not shown). (C) Diagram of telomere region. $(D)$ Ccq1 is required for association of Trt1 with telomeres. Diploids heterozygous for $c c q 1 \Delta$ and $t r t 1^{+}-m y c$ were sporulated, progeny were cultured and collected, and Trt1-Myc localization was assessed by ChIP. The abundance of Trt1-Myc was assessed by Western blotting of whole-cell extracts (WCE). (Left panel) Cdc2 served as loading control. The indicated strains were immunoprecipitated (IP) with anti-myc antibody, and DNA fragments in the immunoprecipitate were quantified using qPCR. (Right panel) Data were normalized to qPCR values obtained from WCE (ChIP percentages are shown in Supplemental Fig. S1) and expressed as fold-enrichment compared with the values obtained from cross-linked wild-type (untagged) cells; the average and standard deviation of three independent experiments are shown. (E) Ccq1 associates with Trt1. WCE were immunoprecipitated with anti-Flag antibody to purify the Ccq 1 complex, and the resulting immunoprecipitates were probed with anti-Flag or anti-Myc. To assess RNase sensitivity, $30 \mu \mathrm{g} / \mathrm{mL}$ RNase was added during immunoprecipitation. For WCE, volumes equivalent to $0.5 \%$ (Myc) or $5 \%$ (Flag) of the corresponding immunoprecipitation volumes were loaded. (e) Extracts from cells containing only the indicated single tagged protein; such extracts were mixed to assess whether Ccq1-Trt1 interaction occurred in vivo or post-extraction. Trt1-Myc was detected in Ccq1-Flag complexes only in lysates of cells containing both tagged proteins. As negative controls, neither $\alpha$-tubulin nor histone H3 were detected in Ccq1-Flag immunoprecipitations (data not shown).

depends on Ccq1. To investigate this possibility, heterozygous $c c q 1^{+/ \Delta}$ diploids carrying endogenously expressed Myc-tagged Trt1 (Trt1-Myc) were sporulated, and the ccq1 $1 \Delta$ offspring were subjected to chromatin immunoprecipitation analysis (ChIP) from $4 \mathrm{~d}$ post-germination onward. Enrichment of telomere fragments was assessed by quantitative real-time PCR (qPCR). While Trt1 clearly associates with telomeric DNA in asynchronous cultures of wild-type cells, it cannot be detected in early ccq1s cells, even though it is stably expressed and telomerebound Rap1 is readily detectable (Fig. 1D; Supplemental Fig. S1). Thus, Ccq1 is essential for recruitment of telomerase to telomeres.

As Ccq1 is required for telomerase recruitment, we asked whether it interacts with Trt1. Indeed, endogenously tagged Ccq1-Flag coimmunoprecipitates with Trt1-Myc (Fig. 1E). This interaction is resistant to treatment with RNase A, indicating that it is not bridged by TER1. When extracts of strains harboring only singly tagged Ccq1-Flag or Trt1-Myc, respectively, are mixed, no interaction between Ccq1 and Trt1 is seen. Hence, the interaction we observe between Ccq1 and Trt1 occurs in vivo and not post-extraction. In addition, Miyoshi et al. (2008) have shown recently that Pot1 interacts with Ccq1 via mutual Tpz1 binding; they also found that Ccq1 was required for association of active telomerase with Tpz1. In agreement with these results, we confirmed that Ccq1 coimmunoprecipitates with Pot1 (data not shown). Collectively, these results suggest that Ccq1 mediates the recruitment of telomerase to telomeres via interaction with Trt 1 and Pot1.

Whereas the majority of $t r t 1 \Delta$ cells eventually lose all telomeric DNA, ccq1 $\Delta$ cells appear to maintain short telomeres. To follow telomere attrition in ccq1s cells more extensively, tetrads from heterozygous $c c q 1^{+/ \Delta}$ diploids were dissected, and the telomere lengths of $c c q 1 \Delta$ progeny were examined over a period of $4 \mathrm{wk}$. After $3 \mathrm{~d}$, none of the progeny show visible defects (Fig. 2A). The telomeres of $c c q 1 \Delta$ cells reach a minimum size within $10 \mathrm{~d}$ (hereafter, we refer to cells bearing critically short telomeres at this stage as "later"), and this short telomere length is maintained for at least 3 wk (Fig. 2B; 
A

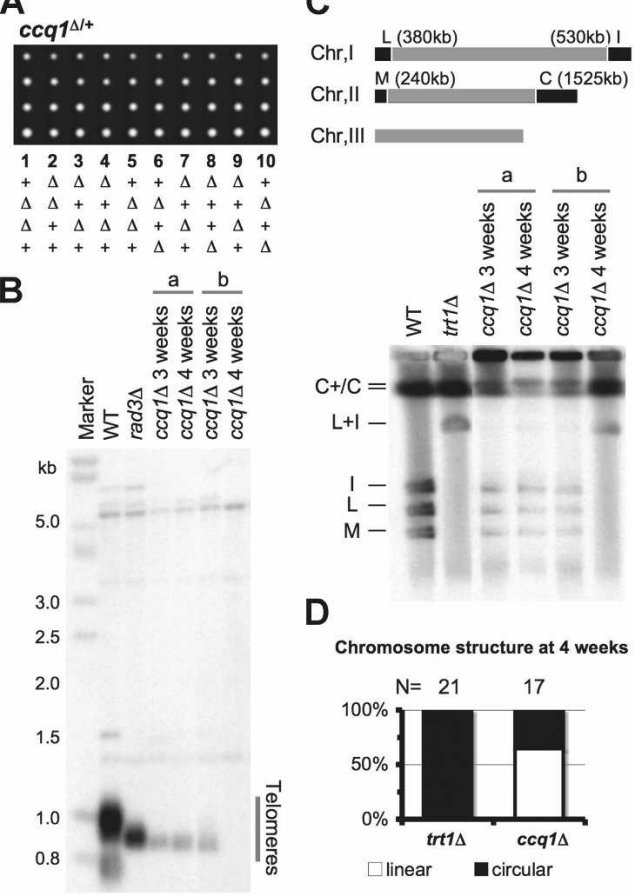

Figure 2. $c c q 1 \Delta$ cells maintain short telomeres. $(A) c c q 1^{+}$deletion does not confer a growth defect upon germination. Tetrads from $c c q 1::$ kanMX6/+ diploids were dissected; colonies harboring the $c c q 1^{+}$deletion are indicated below by the $\Delta$ symbol. $(B)$ ccq1s cells maintain extremely short telomeres, and some eventually lose telomeres entirely. Individual $c c q 1 \Delta$ clones (of which $\mathrm{a}$ and $\mathrm{b}$ are representative examples) from $(A)$ heterozygous diploids were grown for $4 \mathrm{wk}$ by restreaking on solid media every $3 \mathrm{~d}$, and their telomere lengths at 3 and 4 wk were assessed as in Figure 1. (C) ccq1s cells maintain linear chromosomes for several weeks. (Top) Depiction of locations and sizes of telomeric NotI restriction fragments (black bars). (Bottom) Genomic DNA from clones a and $\mathrm{b}$ in $B$ was digested with NotI and subjected to PFGE. NotI fragments containing chromosome ends (L, M, I, and C), as well as fusion fragments representing circular chromosomes $(\mathrm{L}+\mathrm{I})$, are indicated to the left of the gel. Note: Fusions involving the $\mathrm{C}$ fragment cannot be resolved from unfused $\mathrm{C}$ fragments under the conditions used $(\mathrm{C}+/ \mathrm{C})$. (D) Two modes of chromosome maintenance in $c c q 1 \Delta$ cells at $4 \mathrm{wk}$. The percentage of clones carrying linear versus circular chromosomes at $4 \mathrm{wk}$ (described in $B$ ) is represented as a distribution graph.

Supplemental Fig. S2). The telomere length of these later ccq1s cells is shorter than that of rad3s cells $(\operatorname{Rad} 3$; ATR homolog), which harbor the shortest telomeres so far observed in fission yeast (Dahlen et al. 1998); this telomere length corresponds to that observed in $\operatorname{trt} 1 \Delta$ cells just before crisis (Fig. 2B; Supplemental Fig. S2). After $4 \mathrm{wk}, 35 \%$ of $c c q 1 \Delta$ cell cultures lose all telomeric DNA. Pulsed-field gel electrophoresis (PFGE) analysis confirmed that these cells lack linear chromosomes and instead harbor circular chromosomes, as is generally observed in trt1 $1 \Delta$ survivors isolated on solid media (Fig. 2B-D; Nakamura et al. 1998). These survivors lack telomeric repeats, indicating that chromosomal fusions oc- cur after the loss of telomeric DNA (Fig. 2C; data not shown). Thus, ccq1 $1 \Delta$ cells fail to recruit telomerase to telomeres and display progressive telomere shortening, yet the majority of $c c q 1 \Delta$ cells ultimately maintain critically short telomeres.

\section{Ccq1 is not involved in chromosomal bouquet formation per se}

Ccq1 was first reported as a bouquet protein that links telomeres to the meiotic SPB (Flory et al. 2004). However, the foregoing observations raised the possibility that the apparent role of Ccq1 in bouquet formation is rather a secondary consequence of telomere attrition (which would abolish the ability of the Taz1-Rapl complex to bind telomeres and confer bouquet formation). Ccq1 localizes throughout the nucleoplasm and accumulates at telomeres (Fig. 3A; Flory et al. 2004). To determine whether Ccq1 localization depends on Taz1, Ccq1 was endogenously tagged with mCherry (Shaner et al. 2004). In vegetative cells, Ccq1-mCherry colocalizes with Pot1-YFP, whether or not Taz1 is present (Fig. 3A). To determine whether the association of Ccql with the meiotic SPB depends on the bouquet proteins, we monitored localization of Ccq1-YFP along with the SPB marker Sid4-mCherry. During the bouquet stage, Ccq1 accumulates at the meiotic SPB (Fig. 3B; Flory et al. 2004). In the bouquet-defective mutants bqt1s, bqt2s, rap1 $\Delta$, and taz1s, Ccq1 foci remain at the nuclear periphery, where telomeres are expected to localize, but not at the SPB (Fig. 3B; data not shown). These results indicate that Ccq1 is not a bouquet protein per se, but rather a telomeric protein.

We next determined whether $c c q 1^{+}$deletion affects the localization of telomere or bouquet proteins. Bqt1, Bqt2, Taz1, and Pot 1 all localize normally to the SPB and telomeres in the absence of Ccq1 (Fig. 3C; data not shown). Furthermore, bouquet formation is intact throughout meiotic prophase, and telomere fireworks (the end of the bouquet stage) (Tomita and Cooper 2007) occur normally (data not shown). These results indicate that Ccq1 is not directly involved in the formation of the chromosomal bouquet.

\section{Meiotic and mitotic chromosome segregation defects in ccq1 $\Delta$ cells harboring short telomeres}

Early ccq1 $1 \Delta$ cells show not only normal bouquet, SPB, and spindle behavior but also normal meiotic chromosome segregation (Fig. 3B,C; data not shown). However,

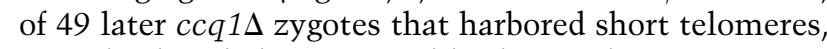
$37 \%$ displayed chromosomal bridges and meiotic segregation defects, and 33\% showed chromosomal bridges but eventually segregated their chromosomes properly (Fig. 4A; data not shown). These occur against a backdrop of normal SPB and spindle behavior (which indicates normal bouquet formation) and are reminiscent of a fraction of taz1s single-mutant meioses, in which NHEJ-mediated telomere-telomere fusions lead to meiotic chromosome missegregation. Such missegregation is suppressed by deletion of $l i g 4^{+}$, the ligase required for NHEJ, in 
A

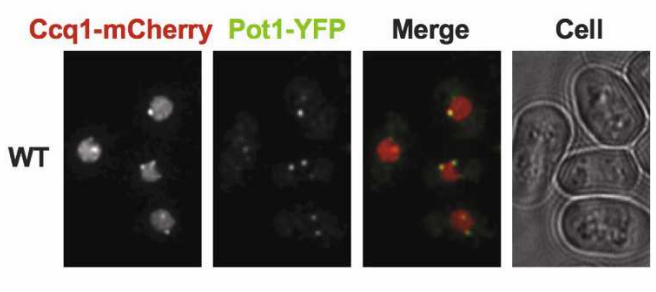

B

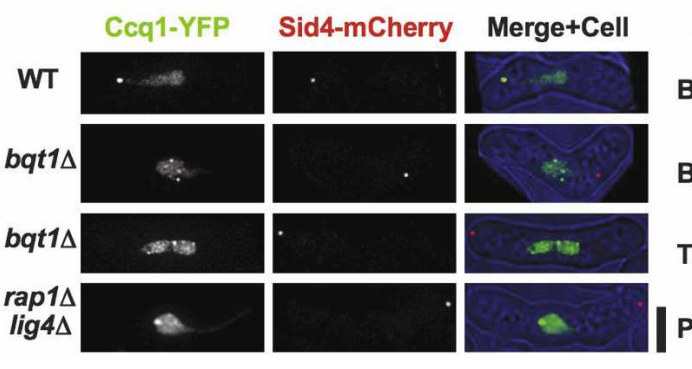

C
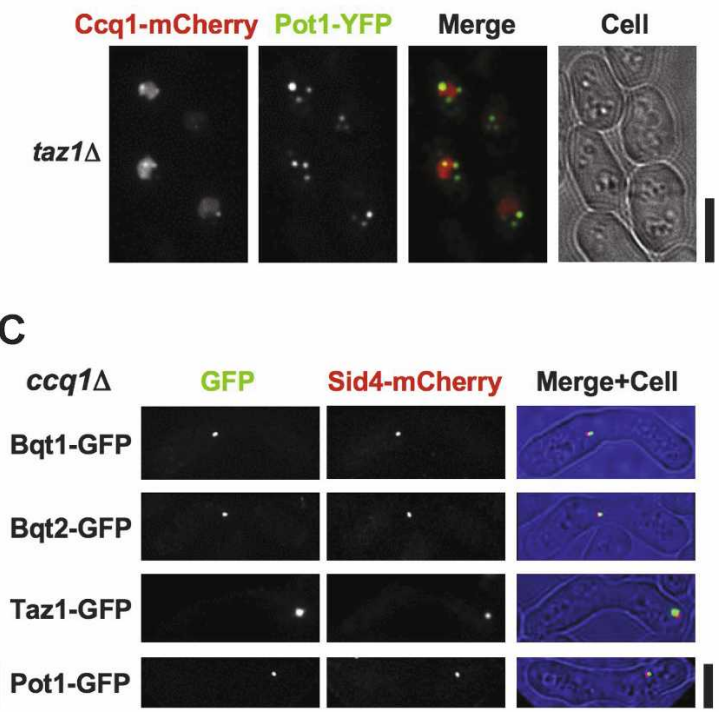

Figure 3. Ccq1 is not involved in bouquet formation or function per se. (A) Ccq1 localizes to telomeres independently of Taz1. Ccq1 and Pot 1 are endogenously tagged with mCherry and YFP, respectively. Ccq1-mCherry and Pot1-YFP foci colocalize in proliferating wild-type and taz1 $\Delta$ cells. Ccq1-mCherry also stains nuclei diffusely. Bar, $5 \mu \mathrm{m}$. $(B)$ Ccq1 localizes to the SPB only when the bouquet forms. Ccq1 and the SPB component Sid4 were endogenously tagged with YFP and mCherry, respectively. Images of meiotic prophase are shown. Ccq1 foci fail to localize to the SPB in bouquet-defective backgrounds. Bar, $5 \mu \mathrm{m}$. $(C)$ Ccq1 is not required for bouquet formation. Bqt1, Bqt2, Taz1, and Pot1 were endogenously tagged with GFP. The indicated GFP foci colocalize with Sid4-mRFP (mCherry) during meiotic prophase in $c c q 1 \Delta$ zygotes. Bar, $5 \mu \mathrm{m}$.

taz1s cells but not in ccq1s cells (Fig. 4A; Ferreira and Cooper 2001; Tomita and Cooper 2007; data not shown). This observation is consistent with the idea that $c c q 1 \Delta$ meiotic defects stem from chromosome end fusions that follow complete telomere loss at a subset of chromosome ends, since, unlike taz1s telomere-telomere fusions, the end fusions that follow complete telomere loss are not dependent on lig4 ${ }^{+}$(Baumann and Cech 2000). Alternatively, the meiotic segregation defects seen in later $c c q 1 \Delta$ zygotes may stem from the process underlying retention of short telomeres (see below). In either case, the ccq1 $1 \Delta$ meiotic defects are due to critically short telomeres and not to a direct role for Ccq1 in bouquet formation.

Chromosomal bridges and segregation defects are observed in later ccq1s cells not only during meiosis, but also during mitosis. While early ccq1 $1 \Delta$ mitosis appears normal, $\sim 30 \%$ of later ccq1s cells display chromosomal bridges (Fig. 4B, arrow) as well as the so-called "cut" phenotype in which septation occurs without proper chromosome segregation (Fig. 4B, arrowhead). Correspondingly, many later ccq1 $1 \Delta$ cells are aneuploid (Fig. 6C [below], bottom panel). These chromosome segregation defects are likely to confer the sickness of later $c c q 1 \Delta$ cells (Supplemental Fig. S5, see ccq1s colonies at $18 \mathrm{~d}$ ).

\section{Chromosome ends are protected by homologous} recombination $(H R)$ in ccq $1 \Delta$ cells

The persistent maintenance of critically short telomeres in later ccq1s cells is reminiscent of the telomere recombination observed in Type I budding yeast EST sur- vivors (Lundblad and Blackburn 1993). Indeed, the maintenance of linear chromosomes in later ccq1s cells is unaffected by deletion of $\operatorname{trt} 1^{+}$(Fig. 5A). Therefore, later ccq1s cells maintain telomeres through a telomeraseindependent mechanism. To determine which factors are required for later $c c q 1 \Delta$ telomere maintenance, we generated a set of double and triple mutants in which $c c q 1^{+}$and genes involved in HR pathways are deleted. HR is promoted by successive loading of replication protein A (RPA) and Rhp51 (the Schizosaccharomyces pombe Rad51 ortholog) on 3' single-stranded overhangs flanking DNA double-strand breaks (DSBs). MRN and Exol participate in generation of the overhang (Tomita et al. 2003), while Rad22 (Rad52), Rhp54 (Rad54), the Rhp5557 (Rad55-57) complex, and the Swi5 complex assist Rhp51 loading, annealing, and strand invasion (Sung 1994, 1997; Muris et al. 1997; Petukhova et al. 1998; Tsutsui et al. 2001; Akamatsu et al. 2003). The DNA helicases Rqh1 (RecQ ortholog), Srs2, and Fbh1 also control HR (Murray et al. 1997; Wang et al. 2001; Morishita et al. 2005; Osman et al. 2005), with Fbh1 inhibition rescuing the illness of fission yeast rad22 $\Delta$ mutants, presumably by counteracting the inability of these cells to load Rhp51 (Osman et al. 2005). While linear chromosome maintenance was retained in ccq1s cells lacking exo1 $1^{+} \mathrm{rad}_{50}^{+}, \operatorname{rhp} 55^{+}, \mathrm{swi}^{+}, \mathrm{rad} 22^{+}, \mathrm{fbh} 1^{+}$, rad $22^{+}$, and $f b h 1^{+}, s r s 2^{+}$, or $r q h 1^{+}$, circular chromosomes were formed following telomere attrition in

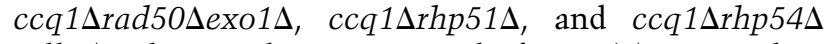
cells (within 2 wk post-removal of Ccq1) (Fig. 5B; data not shown). Hence, the chromosomal ends of later $c c q 1 \Delta$ cells are maintained via the activities of Rhp51 and 54, 

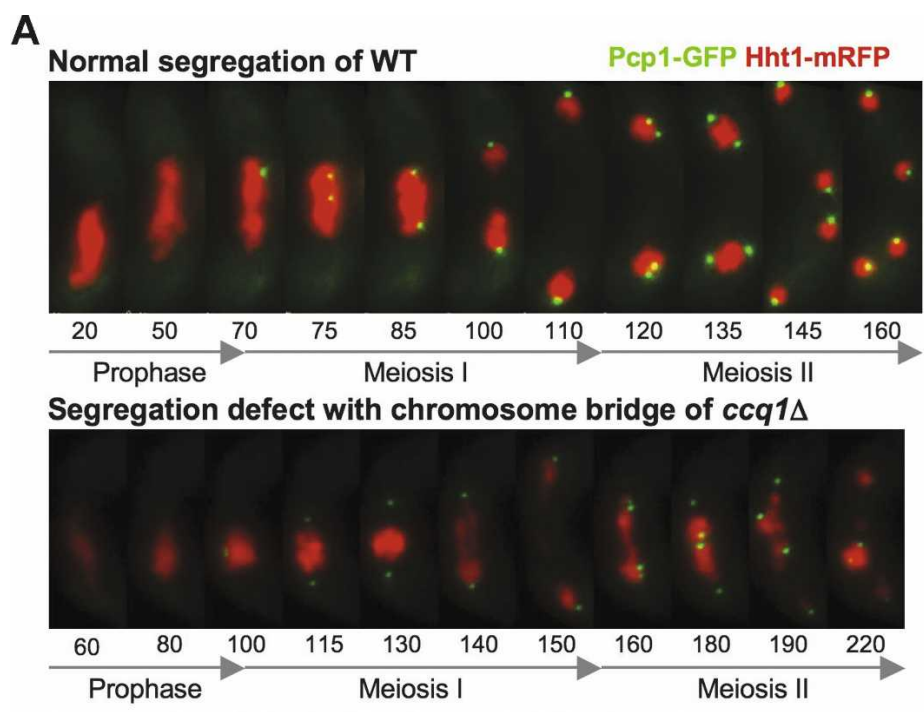

Segregation defect with aberrant SPB of taz1 $\Delta$
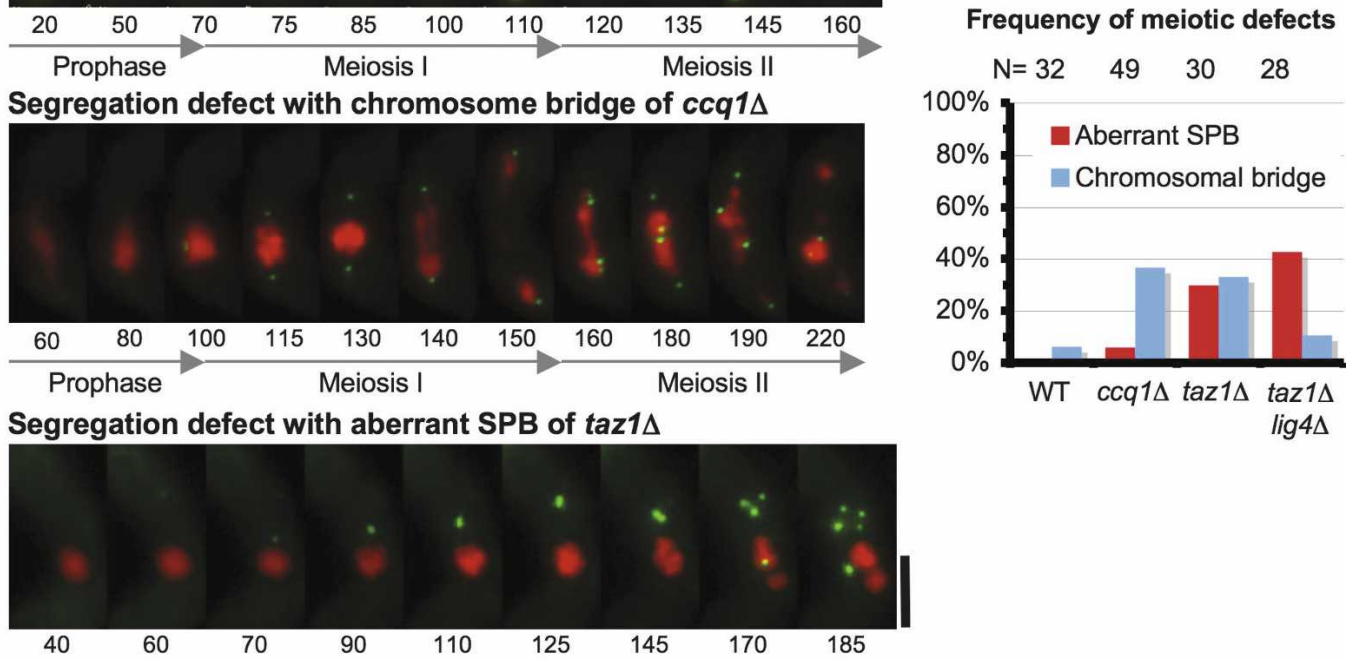

\section{B}

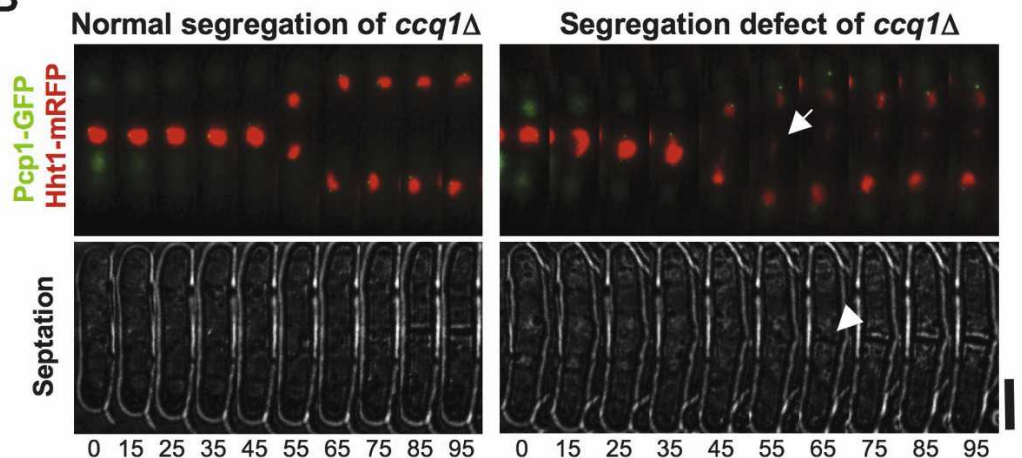

Segregation defects

$\mathrm{N}=15 \quad 15$

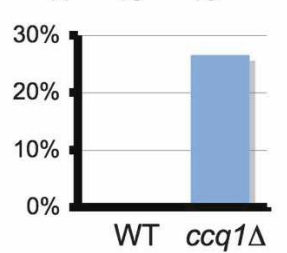

Figure 4. Chromosomal bridge and segregation defects in meiosis and mitosis. $(A)$ Meiotic chromosome segregation patterns in

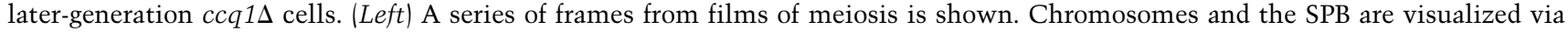
endogenously tagged histone H3 (Hht1-mRFP) and Pcp1-GFP, respectively. The numbers below frames represent minutes elapsed since filming began. Bar, $5 \mu \mathrm{m}$. (Right) Graph showing percentages of the indicated chromosome segregation patterns. Note: Deletion of $l i g 4^{+}$reduces chromosomal bridging in taz1s cells by preventing chromosomal end fusions (Ferreira and Cooper 2001; Tomita and Cooper 2007). (B) A series of frames from films of mitosis in later generation ccq1s cells. Bar, $5 \mu$ m. (Arrow) Chromosome bridge; simultaneous appearance of septum (arrowhead) indicates "cut" phenotype. The table to the right shows the frequency of mitotic segregation defects.

following a resection process that can be conferred by either Rad50 or ExoI; surprisingly, this HR reaction is independent of Rad22.

The continual recombination at ccq1s telomeres, along with the presence of critically short telomeres in ccq1 $\Delta$ cells, suggests that these telomeres are continually recognized as DNA damage and/or may suffer replication defects. To monitor the presence of a DNA damage signal at ccq1 $1 \Delta$ telomeres, Rad11, the large subunit of the RPA complex, was endogenously tagged with GFP. RPA is a known marker of the ssDNA accumulation that accompanies DNA replication, the resection of DSBs prior to HR, ALT telomere maintenance, and excessive telomeric single-strand overhang signals (Gasior et al. 1998; Lisby et al. 2004; Grudic et al. 2007; Kibe et al. 2007). Rad11-GFP is detected diffusely in the nuclei of wild-type cells, $17 \%$ of which display foci, presumably representing those cells in S phase (Fig. 5C). In contrast, $80 \%$ of later ccq $1 \Delta$ cells display RPA foci (Fig. 5C). These foci are brighter and larger than the Rad11 foci in wildtype cells (Fig. 5C), suggesting that they represent clusters containing multiple telomeres. To explicitly address the positions of these foci, colocalization of endogenously Cerulean-tagged Ssb2 (the p30 subunit of RPA) and Taz1- 
A
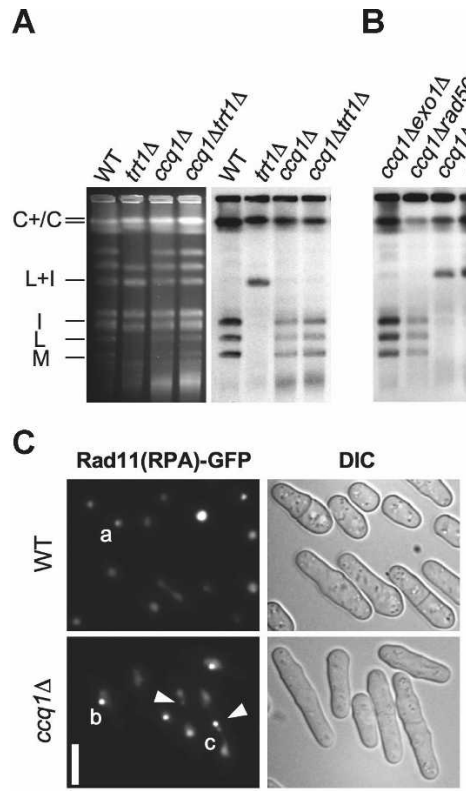

B

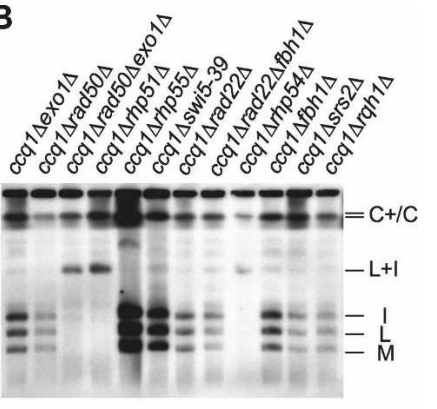

D

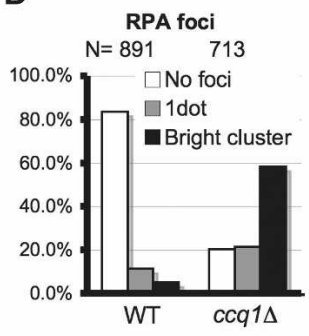

Figure 5. $c c q 1 \Delta$ telomeres are maintained via Rad22-independent HR. (A) Later ccq1s cells maintain chromosome ends without telomerase. The indicated strains were cultured for 2 wk. Chromosome fusions were detected with ethidium bromide (left) andSouthern blotting (right) using L, M, I, and C probes as described in Figure 2C. $(B) c c q 1 \Delta$ telomere maintenance requires Rhp51 and Rhp54 but not $\operatorname{Rad} 22$. It also requires either Rad50 or Exol. See details in $A$. $(C)$ RPA foci remain on chromosomal bridges (arrowheads) in later-generation ccq1s cells. Rad11 was endogenously tagged with GFP and observed in vegetatively growing cells. Bar, $5 \mu \mathrm{m}$. $(D)$ RPA foci are categorized as absent, present in one $\operatorname{dot}(\mathrm{a}$ in $C)$, or present in one or more clusters of bright dots ( $\mathrm{b}$ and $\mathrm{c}$ in $C$, respectively).

YFP was monitored in $c c q 1^{+}$and $c c q 1 \Delta$ cells (Supplemental Fig. S3), the latter of which showed an approximately threefold increase in RPA-Tazl colocalization; note that this value is an underestimate, since Tazl-YFP is often not visible at short ccq1s telomeres. Moreover, RPA foci often appear on chromosomal bridges $148.7 \%$ of mitotic cells) (Fig. 5C, left panel, arrowheads). These foci may represent either or both of two phenomena: First, they may be caused by breakage-fusion-bridge cycles occurring among a subfraction of critically short telomeres in later $c c q 1 \Delta$ cells; this fraction may exist despite the fact that Southern blots do not reveal fused chromosome end fragments at this time point. Alternatively, RPA focus-containing chromosomal bridges in later ccq1s cells may be caused by telomeric replication or recombination intermediates.

The appearance of telomeric RPA foci in ccq1s cells coincides with elevated levels of telomeric $3^{\prime}$ overhang signals in these cells, as assessed by native in-gel hybridization analysis (Supplemental Fig. S7). While wild-type and early ccq1s cells fail to yield detectable hybridization to a probe for either the G-rich or C-rich telomeric single-strand, ccq1 $1 \Delta$ cells yield detectable G-strand signals by $5 \mathrm{~d}$ post-germination. We cannot distinguish whether this overhang signal accumulation is due to the onset of

critical telomere shortening or to a direct role of Ccq1 in controlling resection at moderately short telomeres.

\section{Activation of Chk1 is required for telomere maintenance in ccq1s cells}

Intriguingly, ccq $1 \Delta$ cells start to elongate after $\sim 4 \mathrm{~d}$ (Fig. 6A; Supplemental Fig. S6A), when telomeric DNA signals remain robust. In contrast, trt1 $\Delta$ cells do not elongate until $7 \mathrm{~d}$, despite showing similar rates of telomere attrition (Fig. 1A; Supplemental Figs. S2, S6A; Fig. 6A). As cell elongation is emblematic of cell cycle arrest or delay, we asked which checkpoint pathway is responsible for this elongation and whether checkpoint activation contributes to the sickness of ccq1s cells. Cell elongation is observed in $c c q 1 \Delta$ cells lacking Cds1, the intraS-phase checkpoint kinase, but not in $c c q 1 \Delta$ cells lacking Chk1 (Fig. 6A; Supplemental Fig. S6B). Indeed, Chk1 is phosphorylated in ccq1s cells (Supplemental Fig. S4). Correspondingly, fluorescence-activated cell sorting (FACS) analysis shows that the elongated cells are arrested with $\geq 2 \mathrm{C}$ DNA content, ruling out the possibility of a G1- or early S-phase arrest (Fig. 6C,d). Thus, ccq1s cells activate the DNA damage checkpoint protein Chk1 from $4 \mathrm{~d}$ post-germination onward.

While trt $1 \Delta$ cells form aberrantly shaped colonies during senescence, trt1 $\Delta$ survivors form round colonies post-senescence (Supplemental Fig. S5; Nakamura et al. 1998). In contrast, ccq1s cells continually show misshapen colonies from the onset of critical telomere shortening ( $10 \mathrm{~d})$ onward (Supplemental Figs. S2 and S5). The aberrant shapes of later ccq1 $1 \Delta$ colonies are suppressed by $c h k 1^{+}$deletion (Supplemental Fig. S5), suggesting that Chk1 activation is toxic in later ccq1s cells. However, $c h k 1^{+}$deletion did not change the profile of $c c q 1 \Delta$ growth (Fig. 6B), an initially surprising observation given that activation of Chk1 delays cell cycle progression.

To further understand the nature of $c c q 1 \Delta$ and $c c q 1 \Delta$ $\operatorname{chk} 1 \Delta$ cells, we tested their stress sensitivity using cell

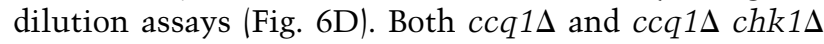
cells grow more slowly than wild-type and $\operatorname{chk} 1 \Delta$ cells at $32^{\circ} \mathrm{C}$. ccq $1 \Delta$ cells display a marked growth defect at $36^{\circ} \mathrm{C}$, indicating temperature sensitivity. Furthermore, although $c c q 1 \Delta$ and $c h k 1 \Delta$ cells do not display cold sensitivity, ccq1 $\operatorname{chk} 1 \Delta$ double-mutant cells are cold sensitive (Fig. 6D, top panel). Likewise, ccq1 $1 \Delta$ cells exhibit only mild sensitivity to the DNA damage-inducing reagents camptothecin (CPT), methylmethane sulfonate (MMS), bleomycin, and hydroxyurea. However, ccq1s chk $1 \Delta$ cells are synergistically sensitive to all of these reagents (Fig. 6D; data not shown).

The cold sensitivity of $c c q 1 \Delta \operatorname{chk} 1 \Delta$ cells is reminiscent of $t r t 1 \Delta$ cells bearing circular chromosomes (Miller and Cooper 2003), as is the DNA damage sensitivity and slow growth (A.K. Heben, D. Jain, K.M. Miller, T.M. Nakamura, T.R. Cech, and J.P. Cooper, in prep.). To deter-

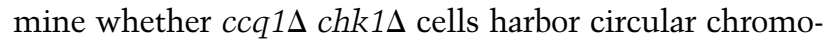
somes, chromosome structure was analyzed using PFGE. Interestingly, while early ccq1s chk $1 \Delta$ cells lose telomeres at the same rate as ccq1 $1 \Delta$ cells, $100 \%(n=4)$ of the 
Figure 6. $c c q 1 \Delta$ cells constitutively activate the ATR-Chk1 DNA damage checkpoint pathway to maintain linear chromosomes. (A) Elongation of later ccq1s cells depends on Chk1. Snapshots were taken at the indicated number of days after germination. $c c q 1 \Delta c d s 1 \Delta$ and $c c q 1 \Delta \operatorname{chk} 1 \Delta$ cells were observed after 13 $\mathrm{d}$ of incubation. Numbers in parentheses indicate mean cell length and standard deviation (in micrometers). See details in Supplemental Figure S6A. (B) Later (2-3 wk) ccq1s cell growth is slower than wild-type growth and is not affected by $\operatorname{chk} 1^{+}$deletion. Logarithmically growing cells were collected every $2 \mathrm{~h}$, and cell density was measured. Error bars represent the standard deviation of three to five independent experiments. $(C)$ FACS analysis of $c c q 1 \Delta$ cell size and DNA content. For G1 and G2 DNA content controls, nitrogen-starved or vegetatively growing wild-type cells were used, respectively. Elongated $c c q 1 \Delta$ cells at day 6 contain 2C DNA content; later $c c q 1 \Delta$ cells contain $\geq 2 \mathrm{C}$ DNA content. $(D)$ $c c q 1 \Delta$ cells are sensitive to higher temperature $\left(36^{\circ} \mathrm{C}\right), \mathrm{CPT}$, and MMS; and ccq $1 \Delta c h k 1 \Delta$ cells are synergistically sensitive to cold $\left(19^{\circ} \mathrm{C}\right)$, $\mathrm{CPT}$, and MMS. After growing cells for $2 \mathrm{wk}$, fivefold serial dilutions of log-phase cultures $\left(0.5 \times 10^{7}\right.$ cells $\left./ \mathrm{mL}\right)$ were stamped on rich media containing the indicated agents and incubated at $32^{\circ} \mathrm{C}$ (except as indicated) for $3 \mathrm{~d}$ (or $5 \mathrm{~d}$ at $\left.19^{\circ} \mathrm{C}\right)$. (E) The Chk1 pathway is required to prevent $c c q 1 \Delta$ chromosome ends' fusions. Cells were grown on rich media at $32^{\circ} \mathrm{C}$ for 2 wk, and their DNA was subjected to PFGE as

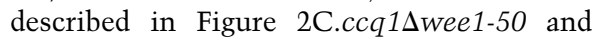

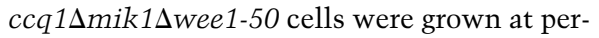
missive temperature $\left(25^{\circ} \mathrm{C}\right)$ for $2 \mathrm{wk}$, then in-

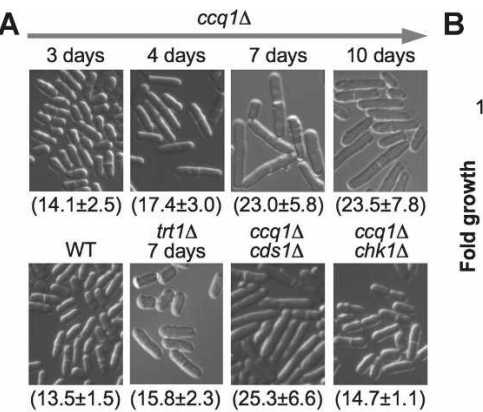

B
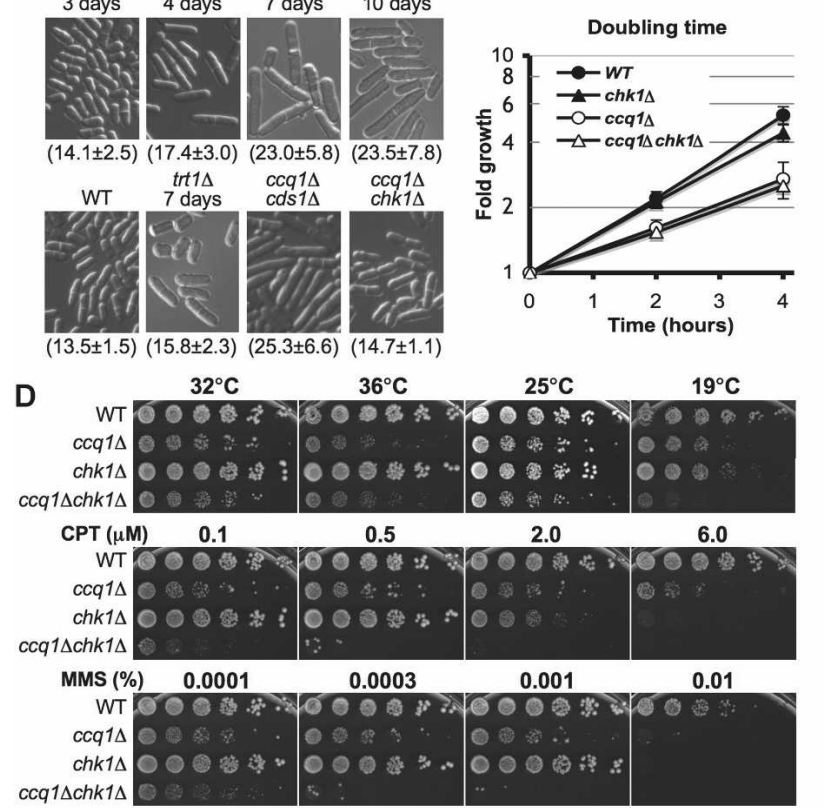

C
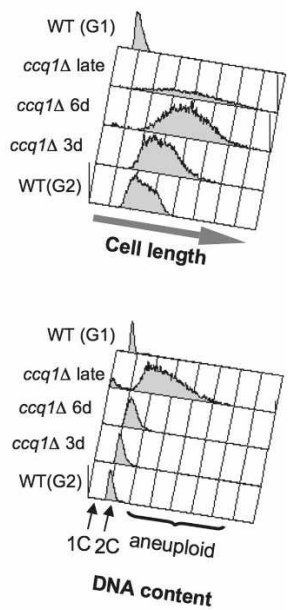

E

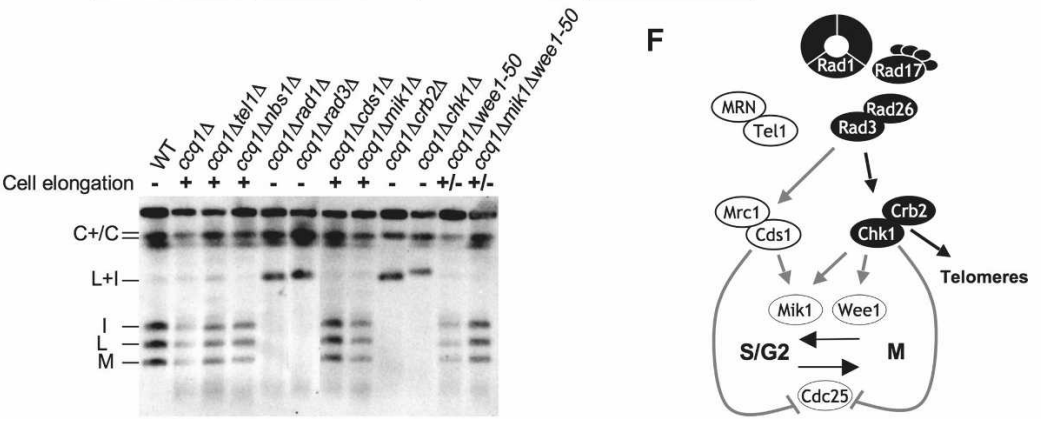

cubated at nonpermissive temperature $\left(32^{\circ} \mathrm{C}\right)$ (Lundgren et al. 1991) for 6 or $12 \mathrm{~h}$ (two or six generations), with identical results. Cell elongation is scored just above the gel lanes and represented as (-) no elongation, $(+)$ elongation, $(+\mid-)$ slight elongation. (F) The DNA damage checkpoint pathways are diagrammed, and the proteins required for ccq1s telomere maintenance are highlighted as black ovals.

double mutants eventually lose telomeres and sustain fusions of chromosomal ends (Figs. 6E; Supplemental Fig. S2). Hence, $c h k 1^{+}$deletion appears to have two opposing effects on the growth rates of $c c q 1 \Delta$ cultures: While Chk1 activation slows cell cycle progression, it also allows the maintenance of linear chromosomes. Loss of Chk1 removes the cell cycle delay, but results in slower growing "circular" ccq1s cultures.

The reliance of $c c q 1 \Delta$ telomere maintenance on Chk1 prompted us to investigate additional checkpoint-associated proteins. An inability to maintain telomeres and suppression of cell elongation are also seen in double mutants of $c c q 1^{+}$and the DNA damage checkpoint genes rad $1^{+}, \operatorname{rad}_{1} 7^{+}$(encoding a subunit of the 9-1-1 clamp and the Rad17 clamp loader, respectively) (Caspari et al. 2000), $\mathrm{rad3}^{+}$, and $\mathrm{crb2}^{+}$(53BP1) (Fig. 6E; Saka et al. 1997; data not shown). These genes have been shown to be required for Chk1 activation. Conversely, other DNA damage checkpoint genes known to be dispensable for Chk1 activationTel1 (ATM) (Naito et al. 1998), Nbs1 (Chahwan et al.
2003), and Cds1-were dispensable for telomere maintenance and cell elongation in ccq1s cells (Fig. 6E).

Activated Chk1 arrests the cell cycle by controlling the activities of Wee1, Mik1, and Cdc25 (Rhind et al. 1997), providing a tool for examining whether cell cycle arrest is a crucial step in maintaining short telomeres in ccq1 $1 \Delta$ cells. Surprisingly, we did not observe telomere

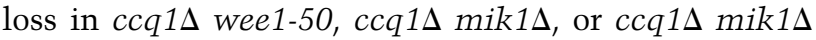
wee1-50 cells (Fig. 6E). Furthermore, ccq1s wee1-50 cells are significantly smaller than $c c q 1 \Delta$ or $c c q 1 \Delta$ chk1s cells and ccq1s wee1-50 cells have shorter doubling times than ccq1s cells (Supplemental Fig. S6C). Hence, we conclude that Chk1 functions directly in the maintenance of $c c q 1 \Delta$ telomeres and does not promote telomere maintenance via arresting cell cycle progression.

ccq $1 \Delta$ taz1 $1 \Delta$ cells resemble trt $1 \Delta$ taz $1 \Delta$ cells, but activate Chk1

taz1s and rap $1 \Delta$ cells respond differently to loss of Trt1 (Nakamura et al. 1998; Miller et al. 2006), and we won- 
A
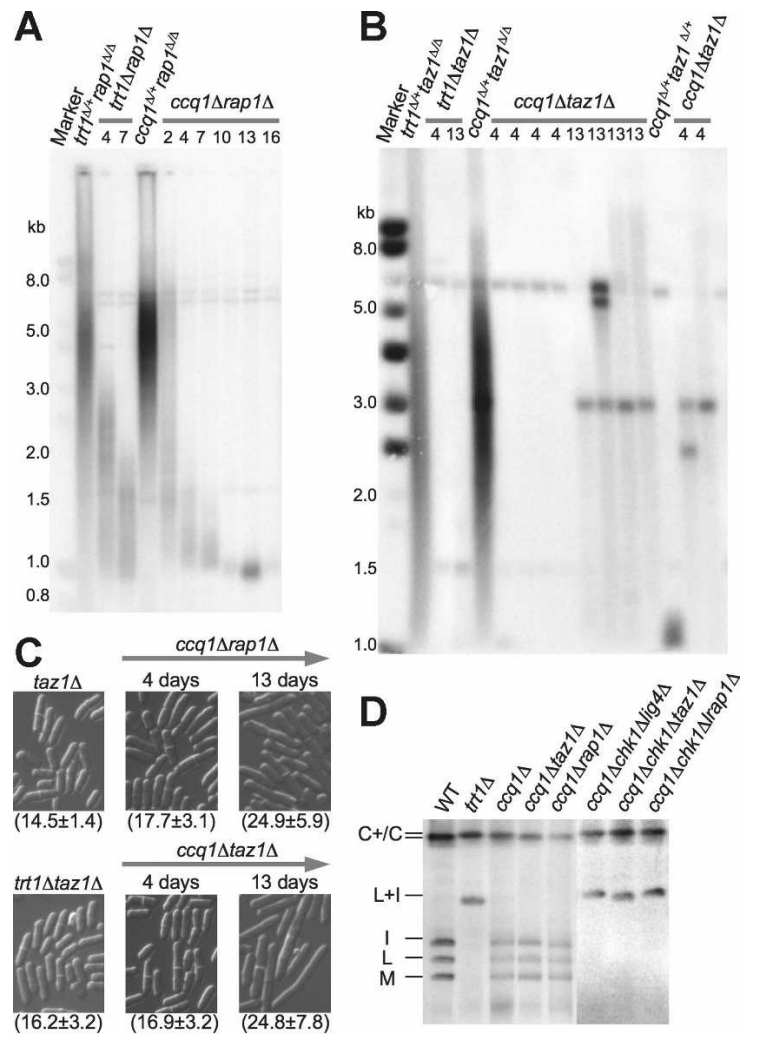

Figure 7. Ccq1 prevents Chk1 activation in rap1s and taz1s cells. (A) Gradual shortening of long rap1s telomeres is observed upon $c c q 1^{+}$deletion. Numbers indicate days post-germination. Diploid heterozygous for $c c q 1^{-}(c c q 1::$ hygMX6/+) or trt1 $1^{-}\left(\operatorname{trt} 1::\right.$ hygMX6/+) and homozygous for rap1s $\left(\mathrm{rap}^{\Delta / \Delta}\right)$ were sporulated, and progeny was collected under selection for $c c q 1 \Delta$ or trt1 $\Delta$. Colonies were restreaked on solid media every $3 \mathrm{~d}$, and at each time point were grown in liquid for $1 \mathrm{~d}$ to collect geno-

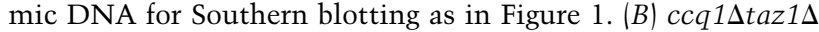
cells lose telomeres immediately. The indicated strains were generated in a manner analogous to $A$ and successively restreaked, and telomere length was analyzed at the indicated number of days. $(C) c c q 1 \Delta t a z 1 \Delta$ and $c c q 1 \Delta$ rap $1 \Delta$ cells progressively increase in length. Numbers in parentheses indicate mean cell length \pm standard deviation (in micrometers). See details in Supplemental Figure S6D. (D) Neither Taz1, Rap1, nor

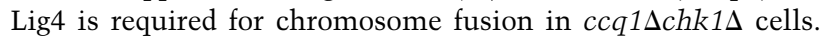
Chromosome fusions were observed as in Figure 2C.

dered whether loss of Ccq1 would recapitulate this phenomenon. In the absence of Ccq1, long rap1s telomeres gradually shorten, and short telomeres are eventually maintained, suggesting that Rap1 is not required for the recombination-based maintenance of ccq1s telomeres

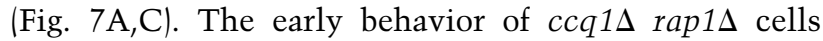
resembles that of trt1 $\operatorname{rap} 1 \Delta$ cells, while the later behavior contrasts with the telomere loss and chromo-

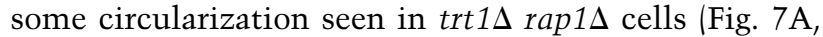
Miller et al. 2006); hence, Ccq1 appears to prohibit recombination-based telomere maintenance in trt1s

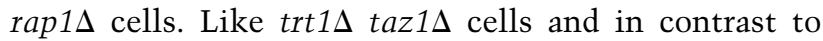

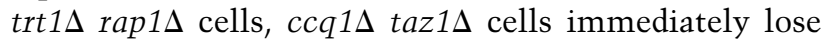
the bulk of the telomere signal, and a variable pattern of telomere signal hybridization appears (Fig. 7B). These results confirm a role for Ccq1 in recruiting telomerase.

$c c q 1 \Delta$ cells become longer and longer with successive generations, suggesting that the duration of Chk1 activation becomes progressively longer (Fig. 5A; Supplemental Fig. S6A). This Chk1-dependent cell elongation in ccq1s cells is abolished when cells lose telomeric DNA and obtain circular chromosomes (Supplemental Fig. S6A), indicating that persistent checkpoint activation stems from chromosomal ends. Progressive cell elongation is also seen upon Ccq1 loss in taz1s and rap1s backgrounds (Fig. 7C; Supplemental Fig. S6D). Intriguingly, cell size starts to increase prior to critical telomere shortening in the $c c q 1 \Delta$ rap $1 \Delta$ background (see $4 \mathrm{~d}$ in Fig. 7A). Activation of Chk1 in ccq1s cells is not a necessary consequence of the accumulation of $3^{\prime}$ telo-

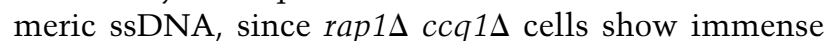
levels of overhang accumulation well in advance of checkpoint activation (Supplemental Fig. S7). Further-

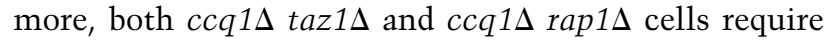
Chk1 for telomere maintenance (Fig. 7D). As expected for chromosome end fusions that follow complete telomere loss, the end fusions observed in ccq1 $1 \Delta$ cells lacking Chk1 are not dependent on Ligase IV (Fig. 7D). Thus, in the absence of Ccq1, activated Chk1 persists through many generations and is crucial for maintaining chromo-

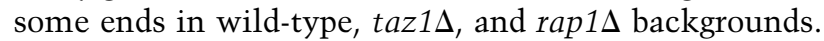

\section{Discussion}

Previous work showed that ccq1 $1 \Delta$ cells display short telomeres, aberrant cellular and nuclear shapes, and defective meiosis (Flory et al. 2004). Our data reveal the two primary functions of Ccq1: recruitment of telomerase to telomeres and suppression of ATR target activation at moderately short telomeres. At early time points following $c c q 1^{+}$deletion, no morphological defects are observed. However, such defects appear with time. As telomeres gradually shorten due to the loss of telomerase engagement, a telomerase-independent mechanism for the maintenance of chromosome integrity commences. This mechanism comprises a Rad22-independent HR pathway that relies on Rhp51, Rhp54, MRN/ExoI, and Chk1. Intriguingly, Chk1 plays a noncanonical role in this HR, as abolition of Chk1-mediated cell cycle arrest, via mutation of the Chk1 targets that control CDK activity, fails to diminish HR at $c c q 1 \Delta$ telomeres. While this HR maintains very short telomeres in the bulk of ccq1 $1 \Delta$ cells, chromosome circularization is observed in $\sim 35 \%$ of very old ccq1s cultures. These cultures also exhibit a Chk1-dependent cell cycle arrest that precedes detectable levels of critical telomere shortening but nonetheless originates from chromosome ends, since cell elongation is no longer observed in $c c q 1 \Delta$ cells that circularize their chromosomes. Ccq1 does not directly participate in meiotic bouquet formation, but influences meiosis via its role in telomere maintenance; the previously reported

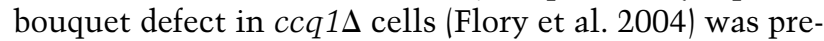
sumably observed after substantial telomere loss. Thus, Ccq1 is a crucial player in telomere metabolism, acting 
not only to recruit telomerase to the chromosome end, but also to restrain Chk1-mediated HR and checkpoint activity at telomeres.

\section{Ccq1 as a novel telomerase component}

The short telomeres of $c c q 1 \Delta$ cells originate from failure of telomerase recruitment (Fig. 1). Thus far, Trt1, Ter1, and Est1 have been the only genes whose deletion was known to yield an "EST" phenotype in fission yeast; Ccq1 can now be added to this list. Budding yeast Est1 localizes to telomeres during late $S$ phase, when it is required for the localization and activation of Est2 (Taggart et al. 2002). The telomeric overhang binding protein, Cdc13, mediates this late-S-phase binding of Est1 and Est2 (Nugent et al. 1996; Evans and Lundblad 1999; Qi and Zakian 2000; Bianchi et al. 2004). Ccq1 is abundant relative to the telomerase components and appears to associate with telomeres in all cells of asynchronous cultures (Fig. 3A), suggesting that Ccq1 localizes to telomeres throughout the cell cycle. The RNase resistance of Ccq1-Trt1 coimmunoprecipitation suggests that Ccq1 associates with Trt1 independently of Ter1 (Fig. 1E), as is the case for the Est1-Trt1 association (Leonardi et al. 2008; Webb and Zakian 2008). Conceivably, modification of Ccq1, or of its interaction with Pot1, controls the recruitment of fission yeast Est 1 to telomeres in a manner analogous to the recruitment of budding yeast Est1 by Cdc13. Our demonstration that Ccq1 interacts with Trt 1 and Pot 1 and mediates telomerase recruitment, along with the recent identification of the fission yeast Pot1/Tpz1/Ccq1 complex (Miyoshi et al. 2008), provides an entry point for deciphering the telomerase activation pathway in fission yeast.

\section{Ccq1 as regulator of telomere state}

Following loss of Ccq1, checkpoint activation does not occur immediately, but does occur prior to detectable levels of critically short telomeres, and at longer telomere lengths than those that trigger checkpoint activation in trt1 $1 \Delta$ cells. Hence, Ccq1 acts as a modulator of "telomere state" in a manner reminiscent of TRF2, whose overexpression allows unusually short telomeres to prevent checkpoint activation (Karlseder et al. 2002). Like TRF2, Ccq1 contributes to the prevention of checkpoint activation at moderately short telomeres, but cannot prevent checkpoint activation once telomeres erode further.

Despite eliciting inappropriate telomeric NHEJ reactions and having extensive telomere overhangs, taz1s and rap $1 \Delta$ telomeres fail to elicit a checkpoint-mediated cell cycle arrest. The relationship between checkpoint activation and telomere attrition in ccq1s taz1s cells cannot be unambiguously assessed since these cells lose telomeres immediately. However, rap1s ccq1s telomeres elicit such an arrest at $4 \mathrm{~d}$ post-germination, despite showing robust telomere restriction fragment lengths by Southern blotting at this time. Hence, Ccq1 suppresses checkpoint activation at rap1s telomeres once a small subset of them becomes moderately short.

\section{Activated Chk1 initiates and maintains telomeric recombination in ccq $1 \Delta$ cells}

Although ccq1s cells are telomerase-defective, latergeneration $c c q 1 \Delta$ cells clearly differ from $\operatorname{tr} t 1 \Delta$ cells. The majority of trt1s survivors contain circular chromosomes generated via intra-chromosomal end fusions; a minority of survivors use HR-mediated telomere maintenance, which confers faster growth than circular chromosomes. These HR-based trt1 $\Delta$ survivors are detected only in liquid cultures that allow the domination of faster-growing cells (Nakamura et al. 1998). Conversely, ccq1s cells always maintain short telomeres via recombination, although a subset eventually sustain chromosome circularization, an "irreversible state." Thus, Ccq1 is a potent inhibitor of recombination-mediated telomere maintenance in telomerase-negative cells. Since Chk1 has been shown to phosphorylate and stabilize Rad51 at sites of damage (Sorensen et al. 2005; Collis et al. 2007) and Chk1 is crucial for ccq1s telomeric recombination, we propose that in the absence of Ccq1, activated Chk1 confers Rhp51-mediated telomere maintenance; in the presence of Ccq1, this activity of Chk1 is inhibited even at critically short $(\operatorname{trt} 1 \Delta)$ telomeres.

In marked contrast to ccq1s and ccq1s taz1s cells, taz1s trt1 $\Delta$ cells proliferate like wild-type cells and require both Rad22 and Rap1 for telomeric HR (Nakamura et al. 1998; Subramanian et al. 2008). The markedly different requirements for $c c q 1 \Delta$ telomere maintenance indicate that $c c q 1 \Delta$ cells use a distinct telomeric HR pathway (Fig. 5B). Rad22 is not essential for Rhp51-dependent DNA repair when Fbh1 is absent, although it is required for efficient and accurate HR (Osman et al. 2005). Hence, $\mathrm{HR}$ at $c c q 1 \Delta$ telomeres might involve a Fbh1-resistant (and Rad22-independent) Rhp51 loading process; accuracy in such a telomeric HR pathway is neither necessary nor likely.

\section{Perspectives}

Short telomeres recruit telomerase in a manner that involves the PI3-kinases ATM and ATR. Ccq1 is required for telomerase recruitment and for inhibiting ATR checkpoint target activation at moderately short telomeres. The identity of Ccq1 as both a modulator of the telomere senescence setpoint and a telomerase recruiter makes good teleological sense, as the shorter telomeres that engage telomerase are the telomeres whose checkpoint suppression ability is most precarious. Unraveling the mechanisms underlying Ccq1 function will contribute to a high-resolution picture of the events surrounding telomerase activation.

\section{Materials and methods}

Yeast genetics and plasmids for strain construction

All of the strains used for this study are listed in Supplemental Table S1. Cells were grown at $32^{\circ} \mathrm{C}$ (except where noted) in 
standard rich media (YES). Meiosis was induced by inoculating $h^{90}$ strains on malt extract (ME) plates for $9-12 \mathrm{~h}$ at $25^{\circ} \mathrm{C}$. Gene deletions, tag insertions, and replacement of the marker cassette were described previously (Tomita and Cooper 2007). To adapt mCherry, Cerulean (Rizzo et al. 2004) and 3xFlag tagging to the one-step gene insertion method (Bahler et al. 1998), pNXa-mCherry, pNXa-Cerulean, and pNXa-3xFlag were created. To obtain pNXa-mCherry and pNXa-Cerulean, the mCherry and Cerulean open reading frames (ORF) were amplified from plasmids pRSET-B-mCherry (Shaner et al. 2004) and pFA6akanMX-cerulean (Saitoh et al. 2005) using the primer set (5'CCCGGGTTAATTAACGCTAGCATGGTGAGCAAGGGCG AGGAG-3' and 5'-GTCAAGGCGCGCCTCAATCTCTAGAC TTGTACAGCTCGTCCATGCC-3') and used to replace the GFP ORF between the PacI and AscI sites of pFA6a-GFP-kanMX6 (Bahler et al. 1998). To obtain pNXa-3xFlag, two oligonucleotides encoding triple-Flag (5'-TAACGCTAGCATGGGTGACT ACAAGGACGACGATGACAAGGGAGATTACAAAGATGA CGACGATAAGGACTACAAGGACGACGATGACAAGTCT AGATGAGG-3' and 5'-CGCGCCTCATCTAGACTTGTCAT CGTCGTCCTTGTAGTCCTTATCGTCGTCATCTTTGTAA TCTCCCTTGTCATCGTCGTCCTTGTAGTCACCCATGCT AGCGTTAAT-3') were annealed and exchanged for the GFP ORF between the PacI and AscI sites of pFA6a-GFP-kanMX6. For all newly tagged strains, we did not observe any defects in cell cycle progression or cell morphology. Strains harboring Taz1-GFP have slightly elongated telomeres but no other telomeric phenotypes, while Pot1-YFP confers very slight elongation. All other combinations of fluorophores and proteins used herein yield normal telomere length. The C-terminal Flag tag on Ccq1 does not affect telomere length. Strains harbouring Trt1Myc and Rap1-Myc show very slight shortening and elongation, respectively, but these tags have no effect on the rate of telomere shortening on ccq $1^{+}$deletion.

\section{PFGE, Southern blotting, and in-gel hybridization}

PFGE, Southern blotting, and native gel analysis were performed as described previously (Ferreira and Cooper 2001; Tomita et al. 2004). Probes for telomeres and STE1 Southern blotting were described previously (Miller et al. 2006).

\section{Protein extraction and immunoprecipitation}

One-hundred milliliters of logarithmically growing cells were harvested and frozen at $-80^{\circ} \mathrm{C}$. Pellets were suspended in the same volume of HB2 buffer (50 mM HEPES/KOH at $\mathrm{pH} 7.5,140$ $\mathrm{mM} \mathrm{NaCl}, 15 \mathrm{mM}$ EGTA, $15 \mathrm{mM} \mathrm{MgCl}, 0.1 \%$ NP-40, $0.5 \mathrm{mM}$ $\mathrm{Na}_{3} \mathrm{VO}_{4}$ ) containing protease inhibitors $(1 \mathrm{mM}$ dithiothreitol, 1 mM PMSF, $0.1 \%$ Protein inhibitor cocktail set III [Sigma], 0.1 ng/mL MG132 [(Sigma]), $10 \mathrm{U} / \mathrm{mL}$ DNase I (Sigma), $1 \mathrm{U} / \mu \mathrm{L}$ RNasin (Promega), and an equal volume of glass beads. Cells were broken using a Fast Prep machine (Thermo). The resulting supernatant was brought to $30 \mathrm{mg} / \mathrm{mL}$. For immunoprecipitation, cell extracts were incubated with monoclonal anti-Flag M2 antibody (Sigma) for $30 \mathrm{~min}$ at $4^{\circ} \mathrm{C}$ and then incubated with mouse IgG-coated Dynabeads (Invitrogen) for $30 \mathrm{~min}$. After extensive washing, the beads were suspended in SDS loading buffer and subjected to Western blotting with anti-Flag M2 and anti-Myc 9E11 (Cell Signaling).

\section{ChIP}

Cell fixation and immunoprecipitation were performed as described previously (Tomita et al. 2003). Precipitated DNA was quantified using qPCR and was normalized to input genomic
DNA template. DNA-binding efficiency was expressed as the efficiency of ChIP (Supplemental Fig. S1) or fold enrichment compared with the value obtained from cross-linked wild-type cells harboring untagged protein (Fig. 1). Telomeric and act $1^{+}$ regions were detected using the telomeric primer set $\left(5^{\prime}\right.$-CGGC TGACGGGTGGGGCCCAATA-3' and 5'-GTGTGGAATTGA GTATGGTGAA-3') that targets the STE1 region adjacent to telomeres and the act1 primer set (5'-GGATTCCTACGTTGG TGATGA-3' and 5'-GGAGGAAGATTGAGCAGCAGT-3'), respectively.

\section{Cytological analysis and live cell imaging}

Imaging of cell shape and Rad11-GFP foci was carried out using a Zeiss Axioplan 2 Microscope (Carl Zeiss MicroImaging, Inc.) with an attached CCD camera (Hamamatsu). Images were captured and analyzed using Volocity software (Improvision).

Other cell images and live analysis of mitotic and meiotic cells were carried out using a DeltaVision Spectris (Applied Precision) comprising an Olympus IX71 wide-field inverted fluorescence microscope; an Olympus UPlanSApo 100×, NA 1.35, oil immersion objective; and a Photometrics CCD CH350 camera cooled to $-35^{\circ} \mathrm{C}$ (Roper Scientific). Images were captured as described previously (Tomita and Cooper 2007).

\section{Acknowledgments}

We thank our laboratory members for discussion and suggestions on the manuscript; Oliver Fleck, Yasushi Hiraoka, Toru Nakamura, Takashi Toda, and Matthew Whitby for the generous gift of strains; Roger Tsien and Ken Sawin for kindly providing mCherry; Kohta Takahashi for kindly providing Cerulean; and Miguel Godinho Ferreira for critical reading of the manuscript. This work was funded by Cancer Research UK.

\section{References}

Akamatsu, Y., Dziadkowiec, D., Ikeguchi, M., Shinagawa, H., and Iwasaki, H. 2003. Two different Swi5-containing protein complexes are involved in mating-type switching and recombination repair in fission yeast. Proc. Natl. Acad. Sci. 100: $15770-15775$.

Azzalin, C.M., Reichenbach, P., Khoriauli, L., Giulotto, E., and Lingner, J. 2007. Telomeric repeat containing RNA and RNA surveillance factors at mammalian chromosome ends. Science 318: 798-801.

Bahler, J., Wu, J.Q., Longtine, M.S., Shah, N.G., McKenzie III, A., Steever, A.B., Wach, A., Philippsen, P., and Pringle, J.R. 1998. Heterologous modules for efficient and versatile PCRbased gene targeting in Schizosaccharomyces pombe. Yeast 14: $943-951$

Baumann, P. and Cech, T.R. 2000. Protection of telomeres by the $\mathrm{Ku}$ protein in fission yeast. Mol. Biol. Cell 11: 32653275.

Baumann, P. and Cech, T.R. 2001. Pot1, the putative telomere end-binding protein in fission yeast and humans. Science 292: 1171-1175.

Beernink, H.T., Miller, K., Deshpande, A., Bucher, P., and Cooper, J.P. 2003. Telomere maintenance in fission yeast requires an est1 ortholog. Curr. Biol. 13: 575-580.

Bianchi, A. and Shore, D. 2007. Increased association of telomerase with short telomeres in yeast. Genes \& Dev. 21: 17261730.

Bianchi, A., Negrini, S., and Shore, D. 2004. Delivery of yeast telomerase to a DNA break depends on the recruitment 
functions of Cdc13 and Est1. Mol. Cell 16: 139-146.

Bryan, T.M. and Reddel, R.R. 1997. Telomere dynamics and telomerase activity in in vitro immortalised human cells. Eur. J. Cancer 33: 767-773.

Bryan, T.M., Englezou, A., Gupta, J., Bacchetti, S., and Reddel, R.R. 1995. Telomere elongation in immortal human cells without detectable telomerase activity. EMBO J. 14: 42404248.

Caspari, T., Dahlen, M., Kanter-Smoler, G., Lindsay, H.D., Hofmann, K., Papadimitriou, K., Sunnerhagen, P., and Carr, A.M. 2000. Characterization of Schizosaccharomyces pombe Hus1: A PCNA-related protein that associates with Rad1 and Rad9. Mol. Cell. Biol. 20: 1254-1262.

Chahwan, C., Nakamura, T.M., Sivakumar, S., Russell, P., and Rhind, N. 2003. The fission yeast $\operatorname{rad} 32$ (mrel1)-rad50-nbs1 complex is required for the S-phase DNA damage checkpoint. Mol. Cell. Biol. 23: 6564-6573.

Chen, Q., Ijpma, A., and Greider, C.W. 2001. Two survivor pathways that allow growth in the absence of telomerase are generated by distinct telomere recombination events. Mol. Cell. Biol. 21: 1819-1827.

Chikashige, Y. and Hiraoka, Y. 2001. Telomere binding of the Rap1 protein is required for meiosis in fission yeast. Curr. Biol. 11: 1618-1623.

Chikashige, Y., Tsutsumi, C., Yamane, M., Okamasa, K., Haraguchi, T., and Hiraoka, Y. 2006. Meiotic proteins bqt1 and bqt2 tether telomeres to form the bouquet arrangement of chromosomes. Cell 125: 59-69.

Churikov, D., Wei, C., and Price, C.M. 2006. Vertebrate POT1 restricts G-overhang length and prevents activation of a telomeric DNA damage checkpoint but is dispensable for overhang protection. Mol. Cell. Biol. 26: 6971-6982.

Collis, S.J., Barber, L.J., Clark, A.J., Martin, J.S., Ward, J.D., and Boulton, S.J. 2007. HCLK2 is essential for the mammalian S-phase checkpoint and impacts on Chk1 stability. Nat. Cell Biol. 9: 391-401.

Cooper, J.P., Nimmo, E.R., Allshire, R.C., and Cech, T.R. 1997. Regulation of telomere length and function by a Myb-domain protein in fission yeast. Nature 385: 744-747.

Cooper, J.P., Watanabe, Y., and Nurse, P. 1998. Fission yeast Tazl protein is required for meiotic telomere clustering and recombination. Nature 392: 828-831.

Dahlen, M., Olsson, T., Kanter-Smoler, G., Ramne, A., and Sunnerhagen, P. 1998. Regulation of telomere length by checkpoint genes in Schizosaccharomyces pombe. Mol. Biol. Cell 9: $611-621$

de Lange, T. 2005. Shelterin: The protein complex that shapes and safeguards human telomeres. Genes \& Dev. 19: 21002110.

Denchi, E.L. and de Lange, T. 2007. Protection of telomeres through independent control of ATM and ATR by TRF2 and POT1. Nature 448: 1068-1071.

Diede, S.J. and Gottschling, D.E. 1999. Telomerase-mediated telomere addition in vivo requires DNA primase and DNA polymerases $\alpha$ and $\delta$. Cell 99: 723-733.

Evans, S.K. and Lundblad, V. 1999. Est1 and Cdc13 as comediators of telomerase access. Science 286: 117-120.

Feng, J., Funk, W.D., Wang, S.S., Weinrich, S.L., Avilion, A.A., Chiu, C.P., Adams, R.R., Chang, E., Allsopp, R.C., Yu, J., et al. 1995. The RNA component of human telomerase. Science 269: 1236-1241.

Ferreira, M.G. and Cooper, J.P. 2001. The fission yeast Tazl protein protects chromosomes from $\mathrm{Ku}$-dependent end-toend fusions. Mol. Cell 7: 55-63.

Flory, M.R., Carson, A.R., Muller, E.G., and Aebersold, R. 2004. An SMC-domain protein in fission yeast links telomeres to the meiotic centrosome. Mol. Cell 16: 619-630.

Garvik, B., Carson, M., and Hartwell, L. 1995. Single-stranded DNA arising at telomeres in cdc13 mutants may constitute a specific signal for the RAD9 checkpoint. Mol. Cell. Biol. 15: 6128-6138.

Gasior, S.L., Wong, A.K., Kora, Y., Shinohara, A., and Bishop, D.K. 1998. Rad52 associates with RPA and functions with rad55 and rad57 to assemble meiotic recombination complexes. Genes \& Dev. 12: 2208-2221.

Gravel, S., Larrivee, M., Labrecque, P., and Wellinger, R.J. 1998. Yeast $\mathrm{Ku}$ as a regulator of chromosomal DNA end structure. Science 280: 741-744.

Grudic, A., Jul-Larsen, A., Haring, S.J., Wold, M.S., Lonning, P.E., Bjerkvig, R., and Boe, S.O. 2007. Replication protein A prevents accumulation of single-stranded telomeric DNA in cells that use alternative lengthening of telomeres. Nucleic Acids Res. 35: 7267-7278.

Hockemeyer, D., Daniels, J.P., Takai, H., and de Lange, T. 2006. Recent expansion of the telomeric complex in rodents: Two distinct POT1 proteins protect mouse telomeres. Cell 126: 63-77.

Huang, P., Pryde, F.E., Lester, D., Maddison, R.L., Borts, R.H., Hickson, I.D., and Louis, E.J. 2001. SGS1 is required for telomere elongation in the absence of telomerase. Curr. Biol. 11: 125-129.

Kanoh, J. and Ishikawa, F. 2001. spRap1 and spRif1, recruited to telomeres by Tazl, are essential for telomere function in fission yeast. Curr. Biol. 11: 1624-1630.

Karlseder, J., Broccoli, D., Dai, Y., Hardy, S., and de Lange, T. 1999. p53- and ATM-dependent apoptosis induced by telomeres lacking TRF2. Science 283: 1321-1325.

Karlseder, J., Smogorzewska, A., and de Lange, T. 2002. Senescence induced by altered telomere state, not telomere loss. Science 295: 2446-2449.

Kibe, T., Ono, Y., Sato, K., and Ueno, M. 2007. Fission yeast Tazl and RPA are synergistically required to prevent rapid telomere loss. Mol. Biol. Cell 18: 2378-2387.

Le, S., Moore, J.K., Haber, J.E., and Greider, C.W. 1999. RAD50 and RAD51 define two pathways that collaborate to maintain telomeres in the absence of telomerase. Genetics 152: $143-152$.

Lendvay, T.S., Morris, D.K., Sah, J., Balasubramanian, B., and Lundblad, V. 1996. Senescence mutants of Saccharomyces cerevisiae with a defect in telomere replication identify three additional EST genes. Genetics 144: 1399-1412.

Leonardi, J., Box, J.A., Bunch, J.T., and Baumann, P. 2008. TER1, the RNA subunit of fission yeast telomerase. Nat. Struct. Mol. Biol. 15: 26-33.

Li, B., Oestreich, S., and de Lange, T. 2000. Identification of human Rap1: Implications for telomere evolution. Cell 101: 471-483.

Lin, J.J. and Zakian, V.A. 1995. An in vitro assay for Saccharomyces telomerase requires EST1. Cell 81: 1127-1135.

Lingner, J., Cech, T.R., Hughes, T.R., and Lundblad, V. 1997. Three Ever Shorter Telomere (EST) genes are dispensable for in vitro yeast telomerase activity. Proc. Natl. Acad. Sci. 94: 11190-11195.

Lisby, M., Barlow, J.H., Burgess, R.C., and Rothstein, R. 2004. Choreography of the DNA damage response: Spatiotemporal relationships among checkpoint and repair proteins. Cell 118: 699-713.

Lundblad, V. and Blackburn, E.H. 1993. An alternative pathway for yeast telomere maintenance rescues est1- senescence. Cell 73: 347-360.

Lundgren, K., Walworth, N., Booher, R., Dembski, M., Kirschner, M., and Beach, D. 1991. mik1 and weel cooperate in the 
inhibitory tyrosine phosphorylation of cdc2. Cell 64: 11111122.

Meyerson, M., Counter, C.M., Eaton, E.N., Ellisen, L.W., Steiner, P., Caddle, S.D., Ziaugra, L., Beijersbergen, R.L., Davidoff, M.J., Liu, Q., et al. 1997. hEST2, the putative human telomerase catalytic subunit gene, is up-regulated in tumor cells and during immortalization. Cell 90: 785-795.

Michelson, R.J., Rosenstein, S., and Weinert, T. 2005. A telomeric repeat sequence adjacent to a DNA double-stranded break produces an anticheckpoint. Genes \& Dev. 19: 2546 2559.

Miller, K.M. and Cooper, J.P. 2003. The telomere protein Taz1 is required to prevent and repair genomic DNA breaks. Mol. Cell 11: 303-313.

Miller, K.M., Ferreira, M.G., and Cooper, J.P. 2005. Taz1, Rap1 and Rif1 act both interdependently and independently to maintain telomeres. EMBO J. 24: 3128-3135.

Miller, K.M., Rog, O., and Cooper, J.P. 2006. Semi-conservative DNA replication through telomeres requires Tazl. Nature 440: 824-828.

Miyoshi, T., Kanoh, J., Saito, M., and Ishikawa, F. 2008. Fission yeast Pot1-Tpp1 protects telomeres and regulates telomere length. Science 320: 1341-1344.

Morishita, T., Furukawa, F., Sakaguchi, C., Toda, T., Carr, A.M., Iwasaki, H., and Shinagawa, H. 2005. Role of the Schizosaccharomyces pombe F-Box DNA helicase in processing recombination intermediates. Mol. Cell. Biol. 25: 8074-8083.

Muris, D.F., Vreeken, K., Schmidt, H., Ostermann, K., Clever, B., Lohman, P.H., and Pastink, A. 1997. Homologous recombination in the fission yeast Schizosaccharomyces pombe: Different requirements for the $\operatorname{rhp} 51^{+}, \operatorname{rhp} 54^{+}$and $\operatorname{rad} 22^{+}$ genes. Curr. Genet. 31: 248-254.

Murray, J.M., Lindsay, H.D., Munday, C.A., and Carr, A.M. 1997. Role of Schizosaccharomyces pombe RecQ homolog, recombination, and checkpoint genes in UV damage tolerance. Mol. Cell. Biol. 17: 6868-6875.

Naito, T., Matsuura, A., and Ishikawa, F. 1998. Circular chromosome formation in a fission yeast mutant defective in two ATM homologues. Nat. Genet. 20: 203-206.

Nakamura, T.M., Morin, G.B., Chapman, K.B., Weinrich, S.L., Andrews, W.H., Lingner, J., Harley, C.B., and Cech, T.R. 1997. Telomerase catalytic subunit homologs from fission yeast and human. Science 277: 955-959.

Nakamura, T.M., Cooper, J.P., and Cech, T.R. 1998. Two modes of survival of fission yeast without telomerase. Science 282: 493-496.

Nakamura, T.M., Moser, B.A., and Russell, P. 2002. Telomere binding of checkpoint sensor and DNA repair proteins contributes to maintenance of functional fission yeast telomeres. Genetics 161: 1437-1452.

Nugent, C.I., Hughes, T.R., Lue, N.F., and Lundblad, V. 1996. Cdc13p: A single-strand telomeric DNA-binding protein with a dual role in yeast telomere maintenance. Science 274: 249-252.

Osman, F., Dixon, J., Barr, A.R., and Whitby, M.C. 2005. The F-Box DNA helicase Fbh1 prevents Rhp51-dependent recombination without mediator proteins. Mol. Cell. Biol. 25: 8084-8096.

Petukhova, G., Stratton, S., and Sung, P. 1998. Catalysis of homologous DNA pairing by yeast Rad51 and Rad54 proteins. Nature 393: 91-94.

Qi, H. and Zakian, V.A. 2000. The Saccharomyces telomerebinding protein Cdc13p interacts with both the catalytic subunit of DNA polymerase $\alpha$ and the telomerase-associated Est1 protein. Genes \& Dev. 14: 1777-1788.
Reichenbach, P., Hoss, M., Azzalin, C.M., Nabholz, M., Bucher, P., and Lingner, J. 2003. A human homolog of yeast Est1 associates with telomerase and uncaps chromosome ends when overexpressed. Curr. Biol. 13: 568-574.

Rhind, N., Furnari, B., and Russell, P. 1997. Cde2 tyrosine phosphorylation is required for the DNA damage checkpoint in fission yeast. Genes \& Dev. 11: 504-511.

Rizzo, M.A., Springer, G.H., Granada, B., and Piston, D.W. 2004. An improved cyan fluorescent protein variant useful for FRET. Nat. Biotechnol. 22: 445-449.

Sabourin, M., Tuzon, C.T., and Zakian, V.A. 2007. Telomerase and Tellp preferentially associate with short telomeres in $S$. cerevisiae. Mol. Cell 27: 550-561.

Saitoh, S., Ishii, K., Kobayashi, Y., and Takahashi, K. 2005. Spindle checkpoint signaling requires the mis6 kinetochore subcomplex, which interacts with mad2 and mitotic spindles. Mol. Biol. Cell 16: 3666-3677.

Saka, Y., Esashi, F., Matsusaka, T., Mochida, S., and Yanagida, M. 1997. Damage and replication checkpoint control in fission yeast is ensured by interactions of $\mathrm{Crb} 2$, a protein with BRCT motif, with Cut5 and Chk1. Genes \& Dev. 11: $3387-$ 3400.

Shaner, N.C., Campbell, R.E., Steinbach, P.A., Giepmans, B.N., Palmer, A.E., and Tsien, R.Y. 2004. Improved monomeric red, orange and yellow fluorescent proteins derived from Discosoma sp. red fluorescent protein. Nat. Biotechnol. 22: 1567-1572.

Singer, M.S. and Gottschling, D.E. 1994. TLC1: Template RNA component of Saccharomyces cerevisiae telomerase. Science 266: 404-409.

Smogorzewska, A., van Steensel, B., Bianchi, A., Oelmann, S., Schaefer, M.R., Schnapp, G., and de Lange, T. 2000. Control of human telomere length by TRF1 and TRF2. Mol. Cell. Biol. 20: 1659-1668.

Snow, B.E., Erdmann, N., Cruickshank, J., Goldman, H., Gill, R.M., Robinson, M.O., and Harrington, L. 2003. Functional conservation of the telomerase protein Estlp in humans. Curr. Biol. 13: 698-704.

Sorensen, C.S., Hansen, L.T., Dziegielewski, J., Syljuasen, R.G., Lundin, C., Bartek, J., and Helleday, T. 2005. The cell-cycle checkpoint kinase Chk1 is required for mammalian homologous recombination repair. Nat. Cell Biol. 7: 195-201.

Subramanian, L., Moser, B.A., and Nakamura, T.M. 2008. Recombination-based telomere maintenance is dependent on Tell-MRN and Rap1 and inhibited by telomerase, Taz1, and $\mathrm{Ku}$ in fission yeast. Mol. Cell. Biol. 28: 1443-1455.

Sugiyama, T., Cam, H.P., Sugiyama, R., Noma, K., Zofall, M., Kobayashi, R., and Grewal, S.I. 2007. SHREC, an effector complex for heterochromatic transcriptional silencing. Cell 128: 491-504.

Sung, P. 1994. Catalysis of ATP-dependent homologous DNA pairing and strand exchange by yeast RAD51 protein. Science 265: 1241-1243.

Sung, P. 1997. Yeast Rad55 and Rad57 proteins form a heterodimer that functions with replication protein A to promote DNA strand exchange by Rad51 recombinase. Genes \& Dev. 11: $1111-1121$.

Taggart, A.K., Teng, S.C., and Zakian, V.A. 2002. Est1p as a cell cycle-regulated activator of telomere-bound telomerase. Science 297: 1023-1026.

Takata, H., Tanaka, Y., and Matsuura, A. 2005. Late S phasespecific recruitment of Mre11 complex triggers hierarchical assembly of telomere replication proteins in Saccharomyces cerevisiae. Mol. Cell 17: 573-583.

Teixeira, M.T., Arneric, M., Sperisen, P., and Lingner, J. 2004. Telomere length homeostasis is achieved via a switch be- 
tween telomerase-extendible and -nonextendible states. Cell 117: 323-335.

Tomita, K. and Cooper, J.P. 2007. The telomere bouquet controls the meiotic spindle. Cell 130: 113-126.

Tomita, K., Matsuura, A., Caspari, T., Carr, A.M., Akamatsu, Y., Iwasaki, H., Mizuno, K., Ohta, K., Uritani, M., Ushimaru, T., et al. 2003. Competition between the Rad50 complex and the $\mathrm{Ku}$ heterodimer reveals a role for Exol in processing double-strand breaks but not telomeres. Mol. Cell. Biol. 23: 5186-5197.

Tomita, K., Kibe, T., Kang, H.Y., Seo, Y.S., Uritani, M., Ushimaru, T., and Ueno, M. 2004. Fission yeast Dna2 is required for generation of the telomeric single-strand overhang. Mol. Cell. Biol. 24: 9557-9567.

Tseng, S.F., Lin, J.J., and Teng, S.C. 2006. The telomerase-recruitment domain of the telomere binding protein $\mathrm{Cdc} 13$ is regulated by Meclp/Tellp-dependent phosphorylation. Nucleic Acids Res. 34: 6327-6336.

Tsutsui, Y., Khasanov, F.K., Shinagawa, H., Iwasaki, H., and Bashkirov, V.I. 2001. Multiple interactions among the components of the recombinational DNA repair system in Schizosaccharomyces pombe. Genetics 159: 91-105.

van Steensel, B. and de Lange, T. 1997. Control of telomere length by the human telomeric protein TRF1. Nature 385: 740-743.

van Steensel, B., Smogorzewska, A., and de Lange, T. 1998. TRF2 protects human telomeres from end-to-end fusions. Cell 92: 401-413.

Verdun, R.E. and Karlseder, J. 2006. The DNA damage machinery and homologous recombination pathway act consecutively to protect human telomeres. Cell 127: 709-720.

Wang, S.W., Goodwin, A., Hickson, I.D., and Norbury, C.J. 2001. Involvement of Schizosaccharomyces pombe Srs2 in cellular responses to DNA damage. Nucleic Acids Res. 29: 2963-2972.

Wang, F., Podell, E.R., Zaug, A.J., Yang, Y., Baciu, P., Cech, T.R., and Lei, M. 2007. The POT1-TPP1 telomere complex is a telomerase processivity factor. Nature 445: 506-510.

Webb, C.J. and Zakian, V.A. 2008. Identification and characterization of the Schizosaccharomyces pombe TER1 telomerase RNA. Nat. Struct. Mol. Biol. 15: 34-42.

Wu, L., Multani, A.S., He, H., Cosme-Blanco, W., Deng, Y., Deng, J.M., Bachilo, O., Pathak, S., Tahara, H., Bailey, S.M., et al. 2006. Pot1 deficiency initiates DNA damage checkpoint activation and aberrant homologous recombination at telomeres. Cell 126: 49-62.

Xin, H., Liu, D., Wan, M., Safari, A., Kim, H., Sun, W., $\mathrm{O}^{\prime}$ Connor, M.S., and Songyang, Z. 2007. TPP1 is a homologue of ciliate TEBP- $\beta$ and interacts with POT1 to recruit telomerase. Nature 445: 559-562.

Ye, J.Z., Hockemeyer, D., Krutchinsky, A.N., Loayza, D., Hooper, S.M., Chait, B.T., and de Lange, T. 2004. POT1interacting protein PIP1: A telomere length regulator that recruits POT1 to the TIN2/TRF1 complex. Genes \& Dev. 18: 1649-1654.

Zhu, X.D., Kuster, B., Mann, M., Petrini, J.H., and de Lange, T. 2000. Cell-cycle-regulated association of RAD50/MRE11/ NBS1 with TRF2 and human telomeres. Nat. Genet. 25: 347-352. 


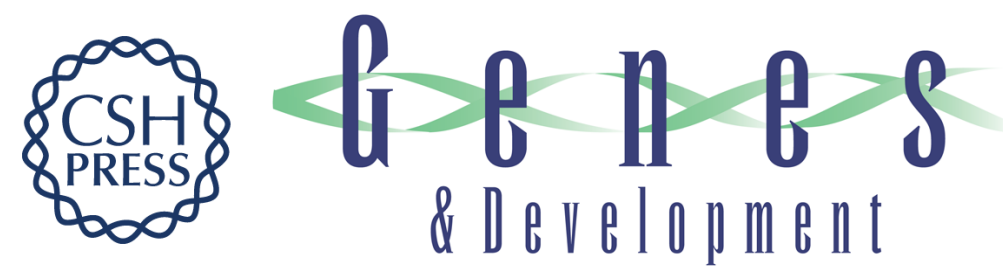

\section{Fission yeast Ccq1 is telomerase recruiter and local checkpoint controller}

Kazunori Tomita and Julia Promisel Cooper

Genes Dev. 2008, 22:

Access the most recent version at doi:10.1101/gad.498608

Supplemental
Material http://genesdev.cshlp.org/content/suppl/2008/12/16/22.24.3461.DC1

References This article cites 96 articles, 46 of which can be accessed free at: http://genesdev.cshlp.org/content/22/24/3461.full.html\#ref-list-1

License

Email Alerting

Receive free email alerts when new articles cite this article - sign up in the box at the top

Service

right corner of the article or click here.

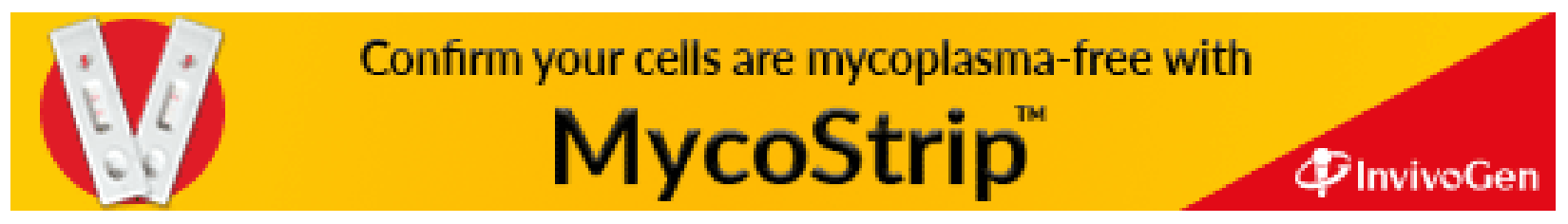

